\title{
Performance enhancement of a compressive thermoelastic cooling system using multi-objective optimization and novel designs
}

\author{
Suxin Qian ${ }^{\mathrm{a}}$, Abdullah Alabdulkarem ${ }^{\mathrm{b}}$, Jiazhen Ling ${ }^{\mathrm{a}}$, Jan Muehlbauer ${ }^{\mathrm{a}}$, Yunho Hwang ${ }^{\mathrm{a}}$, \\ Reinhard Radermacher ${ }^{\mathrm{a}}$ \\ ${ }^{a}$ Center for Environmental Energy Engineering, Department of Mechanical Engineering, \\ University of Maryland, 4164 Glenn L. Martin Hall Bldg., College Park, MD 20742, USA \\ ${ }^{b}$ Department of Mechanical Engineering, King Saud University, PO Box 800, Riyadh 11421, \\ Saudi Arabia \\ *Corresponding Author \\ Tel: (+1) 301-405-5247, Fax: (+1) 301-405-2025, Email: yhhwang@umd.edu
}

\begin{abstract}
Thermoelastic cooling is a recently proposed, novel solid-state cooling technology. It has the benefit of not using high global warming potential (GWP) refrigerants which are used in vapor compression cycles (VCCs). Performance enhancements on a thermoelastic cooling prototype were investigated. A few novel design options aiming to reduce the cyclic loss were proposed. It was found that the maximum temperature lift increased from $6.6 \mathrm{~K}$ to $27.8 \mathrm{~K}$ when applying the proposed novel designs, corresponding to 0 to $152 \mathrm{~W}$ cooling capacity enhancement evaluated under $10 \mathrm{~K}$ water-water system temperature lift. In addition, a multi-objective optimization problem was formulated and solved using the genetic algorithm to maximize the system capacity and coefficient of performance (COP). With all the novel designs, the optimization could further


enhance $31 \% \mathrm{COP}$, or $21 \%$ cooling capacity, corresponding to COP of 4.1 or $184 \mathrm{~W}$ maximum cooling capacity.

Key words: shape memory alloy, elastocaloric, nitinol, solid-state cooling, genetic algorithm

\section{Nomenclature}

\section{Symbols}

$A$

area $\left[\mathrm{m}^{2}\right]$

COP

coefficient of performance [-]

$c_{p}$

specific heat $\left[\mathrm{J} \cdot \mathrm{g}^{-1} \cdot \mathrm{K}^{-1}\right]$

$D$

diameter $[\mathrm{m}]$

GWP

global warming potential

HR

heat recovery

HTF

heat transfer fluid

$h$

heat transfer coefficient $\left[\mathrm{W} \cdot \mathrm{m}^{-2} \cdot \mathrm{K}^{-1}\right]$

ID

internal diameter $[\mathrm{m}]$

$k$

thermal conductivity $\left[\mathrm{W} \cdot \mathrm{m}^{-1} \cdot \mathrm{K}^{-1}\right]$

$L \quad$ length [m]

$N \quad$ quantity [-]

$O D \quad$ outside diameter [m]

PEEK polyether-ether-ketone

ra nitinol heat transfer area to volume ratio $\left[\mathrm{m}^{-1}\right]$

SMAs shape memory alloys

sec second

$T \quad$ temperature [K]

$t \quad$ time, or duration [sec] 


\section{Subscripts}

$\begin{array}{ll}\text { ad } & \text { adiabatic } \\ \text { bs } & \text { baseline } \\ \text { cyc } & \text { cycle } \\ \mathrm{f} & \text { fluid } \\ \text { HT } & \text { heat transfer } \\ \text { LH } & \text { loading head } \\ \text { s } & \text { solid }\end{array}$

\section{Introduction}

Solid-state cooling technologies are considered as novel alternatives to conventional VCCs, which use high GWP refrigerants. These technologies include the most matured and commercialized thermoelectric cooling (Sharp et al., 2006), the rapidly developing magnetic cooling (Sarlah et al., 2006, Zimm et al., 2006, Jacobs et al., 2014, Bahl et al., 2014), electrocaloric cooling ( $\mathrm{Gu}$ et al., 2013, Jia and $\mathrm{Yu}, 2012$ ), and the most recently proposed thermoelastic cooling (Cui et al., 2012). Although similar concepts have been applied to rubber bands with the same terminology (Fischer et al., 1994, Lyon et al., 1984, Gerlach, 2009), thermoelastic cooling in this study refers to a solid-state cooling system using shape memory 
alloys (SMAs), due to a more promising performance (i.e. latent heat, fatigue) in the material level having been demonstrated when compared to rubber.

Thermoelastic (elastocaloric) cooling is based on the elastocaloric cooling effect discovered in SMAs, which involves a martensitic phase change process induced by stress change. When the SMA is subjected to an external stress exceeding the phase change threshold, which could be caused by uniaxial tension or compression, the original austenite crystal starts to transform into martensite crystal. Meanwhile, latent heat is released, resulting in the temperature increase of the SMA itself. The reverse process takes place as soon as the external stress drops below the threshold, when the martensite changes back to austenite and absorbs the latent heat. This heat absorption process cools down the SMA or a heat transfer fluid (HTF), in order to be further used to meet different cooling loads. Various SMAs with large elastocaloric effects have been discovered in the past. Copper based alloys were binary alloys $\mathrm{Cu}-\mathrm{Zn}$ (Romero and Pelegrina, 2003) and Cu-Sn (Miura et al., 1975), as well as ternary alloys Cu-Zn-Al (Bonnot et al., 2008), Cu-Al-Ni (Picornell et al., 2004) and Cu-Al-Be (Manosa et al., 1993). Ferrous SMAs were also investigated, including Fe-Pd (Xiao et al., 2013) and Fe-Rh (Nikitin et al., 1992). The most promising SMA was Ni-Ti 50\% atom weight, which was also known as nitinol, after its first discovery in The Naval Ordinance Laboratory (Buehler et al., 1963). The most important performance index to compare the applicability of SMAs is the adiabatic temperature span, which is defined as the measurable temperature change in the SMA during the stress induced adiabatic loading/unloading process. Past studies suggested that nitinol had 17 - $23 \mathrm{~K}$ adiabatic temperature span (Cui et al., 2012, Otsuka and Wayman, 1998), whereas the Cu-Zn-Al and Cu-Al-Ni had 11 $19 \mathrm{~K}$ adiabatic temperature span. The nitinol also had much better mechanical superelastic performance than copper based alloys, since copper based alloys were brittle and thus had poor fatigue performance. The major drawback of nitinol compared to copper based SMAs was the 
higher hysteresis (Saburi, 1998), which might be reduced with a small amount of copper (Bechtold et al., 2012).

Applying the advancements in material to a real cooling system with its many components, control, and complexity is quite challenging due to the immaturity of the technology. Keys to successfully building a thermoelastic cooling system include using a very efficient driving system capable of providing small displacement but a huge force, and a highly efficient heat recovery (HR)/regenerator design. In addition, every means available to minimize all possible thermal, pressure, and friction losses need to be considered. The heat recovery process helps to improve the performance since it acts as a precooling before the unloading process. Previous studies already developed the fundamental knowledge for the high efficient HR concept and how to design the HR properly (Qian et al., 2015a). Based on the developed HR method, a full system transient model was developed (Qian et al., 2014). The model predicts the performance of a thermoelastic cooling system, taking into account all real geometries, thermal masses of all the necessary components, and simplified dynamics inside the SMA bed. Furthermore, the model was used to guide the design of a real $100 \mathrm{~W}$ thermoelastic cooling prototype.

Figure 1 introduces the basic cycle concept developed in the previous study (Qian et al., 2015b) for a reversed Brayton thermoelastic cooling system. As shown in Figure 1 (a), the previously designed system consisted of two SMA beds, a driving mechanism between the SMA beds, a heat source, and a heat sink. Three separate HTF loops were used for heat rejection, cooling delivery, and heat recovery. With the valves, pumps, and mechanical driving system operated as designed, the temperature of each SMA bed can be tracked on a $T$-s diagram, as shown in Figure 1 (b). Bed 1 starts with loading (compression) when there is no HTF flowing, corresponding to $1 \rightarrow 1^{\prime} \rightarrow 2$ adiabatic temperature increase process. Bed 1 is then cooled down from 2 to 3 via the heat rejection process. Afterwards, heat recovery processes ( 3 to 4 ) take place by exchanging heat between bed 1 and bed 2 using the HR loop. The HR process precools bed 1 
from 3 to 4 so that the unloading process can reach lower temperatures, and results in higher cooling capacity. The second half of the cycle is a reverse process compared to the first half, including an unloading (decompression), cooling delivery, and heat recovery process for bed 1.

The motivation of this study is due to the major issue that the system COP was predicted to be only 1.7 with temperature lift under $10 \mathrm{~K}$ (Qian et al., 2015b). It worsened when the parameters of the transient model were modified to consider all the metal thermal mass using the developed thermoelastic cooling prototype geometries. The results showed that only $6.6 \mathrm{~K}$ temperature lift was achievable with the modification (Qian et al., 2015 b). One way to understand the challenge is to plot the known losses inside the system stage by stage, before discussing details of performance improvements. As shown in Figure 2, the five stages' losses were broken down from Carnot COP down to the system COP. The lowest COP was zero because the maximum achievable temperature lift was $6.6 \mathrm{~K}$. Clearly, material scientists carry the most important and significant burden to reduce the first stage's loss. While the Stirling cycle with isothermal loading/unloading is difficult to approach, the second stage loss can be partially eliminated at least by applying hybrid cycle design, which will be discussed in a future study. The third stage's loss is fixed due to the current state of the art mechanical driving system efficiency, unless breakthrough occurs in these components. All the above mentioned three losses are beyond the scope of this study, which lowers the COP from 28 to 5.6. Here, our focus is minimizing the heat transfer loss and the cyclic loss, which are closely related to the system level heat transfer and heat recovery processes.

Hence, the objective of this study is to resolve the unnecessary cyclic loss and heat transfer loss on the system level by introducing novel designs and applying an optimization method. Several novel designs are introduced first, together with their corresponding model modification details. The system performance improvement with the novel designs are then evaluated. The baseline model and the modified model in this study are validated with experimental data before 
conducting optimization. Then the multi-objective optimization method is used to further enhance the system performance. The results from this study will be implemented in two different sized thermoelastic cooling prototypes, which are currently under development.

\section{Novel Design Options}

The novel designs introduced in this study focus on reducing the cyclic loss caused mostly by unnecessary dead thermal masses inside the system. Figure 3 is a schematic of the original design of a single SMA bed assembly using nitinol tubes to produce cooling and heating capacity. Both beds share the same symmetric design. Under ideal circumstances, the only necessary part in Figure 3 is the red tubes bundle in the middle, where anything else can be regarded as dead thermal mass since they do not generate useful cooling nor heating. The tubes' holders were designed to sustain radial direction stress from the nitinol tubes during the compression process, as well as avoid buckling. The two loading heads were originally designed to feed HTF into each of the nitinol tubes for heat transfer, then transfer the compression force directly into the nitinol tubes. In the original design, the top hexagon part of the loading head has multiple HTF flowing channel holes corresponding to each of the nitinol tubes inside. The HTF holes were gathered in another orthogonal channel, which was then connected to the external HTF pipes. The tubes' holders and loading heads were made of enhanced steel and, therefore, improvements are needed to minimize the heat transfer between the nitinol tubes and HTF to the tubes' holders and loading heads. Some important geometries and properties are listed in Table 1.

\subsection{Coating/Insulation Layer for Tubes Holders}

As shown in Figure 3, the nitinol tubes are arranged in a hexagon layout inside the tubes' holders, where the axial conduction takes place between them. This conduction directly absorbs heat during the loading process and releases heat during the unloading process, which neutralizes 
part of the heating/cooling capacity while the heat exchanger process occurs between HTF and nitinol tubes.

To resolve this issue, a layer of low thermal conductivity insulation material, or a thin film of low thermal conductivity coating on the tubes' holders can be applied as a heat resistance. To quantitatively investigate its applicability, the following equation is added to the original model for the film coating/insulation layer.

$$
h_{\text {coating }}=\frac{\beta}{1 / h_{\text {contact }}+\delta_{\text {coating }} / k_{\text {coating }}}
$$

In Eq. (1), $h_{\text {contact }}$ is the contact resistance between the tubes' holders and the nitinol tubes, $\beta$ is the contact area ratio between the tubes' holders and nitinol tubes, since nitinol tubes are only in line contact with the tubes' holders. In this study, $\beta$ was assumed to be 0.1 .

\subsection{Coating/Insulation Layer Design}

The same method can be introduced to the two loading heads. A thin film coating or an insulation layer reduces the heat transfer interaction between the loading head steel part and the HTF flowing inside the nitinol tubes. Similar to Eq. (1), the overall heat transfer coefficient between the HTF and the loading head metal can be expressed in Eq. (2).

$$
h_{\text {coating }, L H}=\frac{1}{1 / h+\delta_{\text {coating }} / k_{\text {coating }}}
$$

In addition, a 2-D model for the loading head was added to take the steel thermal mass into account, as shown in Eq. (3). Noting that the fluid was still modeled as 1-D in Eq. (4).

$$
\begin{aligned}
& \frac{\partial T_{L H}(x, r, t)}{\partial t}=\alpha_{L H}\left[\frac{\partial^{2} T_{L H}(x, r, t)}{\partial x^{2}}+\frac{\partial^{2} T_{L H}(x, r, t)}{\partial r^{2}}+\frac{\partial T_{L H}(x, r, t)}{r \partial r}\right] \\
& \frac{\partial T_{f}(x, t)}{\partial t}=\alpha_{f} \frac{\partial^{2} T_{f}(x, t)}{\partial x^{2}}-u_{f} \frac{\partial T_{f}(x, t)}{\partial x}+\frac{h_{\text {coating }, L H}}{\rho c_{p} \delta_{f}}\left(T_{f}(x, t)-T_{L H}\left(x, t, r=R_{i n}\right)\right)
\end{aligned}
$$




$$
\begin{aligned}
& \left.\frac{\partial T_{L H}(x, r, t)}{\partial x}\right|_{x=0, x=L}=0 \\
& -\left.k_{L H} \frac{\partial T_{L H}(x, r, t)}{\partial r}\right|_{r=R_{\text {out }}}=0 \\
& -\left.k_{L H} \frac{\partial T_{L H}(x, r, t)}{\partial r}\right|_{r=R_{\text {in }}}=h_{\text {coating }, L H}\left(T_{L H}(x, r, t)-T_{f}(x, t)\right) \\
& T_{f}(x=0, t)=T_{f, \text { in }}(t)
\end{aligned}
$$

Eqs. (5-8) are boundary conditions. Eqs. (5-7) assumes adiabatic boundary for the metal loading head, except for the contact side between HTF and metal. Eq. (8) is the inlet boundary condition for HTF.

Similar to the previous developed model (Qian et al., 2014), a finite difference method was used in the updated model developed in Simulink ${ }^{\mathrm{TM}}$ to solve the above set of equations.

A specific design of using a single thermal insulation layer, such as Teflon ${ }^{\circledR}$, is presented in Figure 4 using the mentioned concept. In this design, there is only a single HTF pass inside the top hexagon part of the loading head, which can be insulated by the Teflon insulation layer. The HTF is then distributed by a meshed layer.

This design reduces the heat transfer between the HTF and the metal loading heads significantly; however, it cannot eliminate the heat transfer due to the finite thickness of the insulation layer. In fact, since the HTF diameter cannot be smaller than a certain threshold to guarantee sufficient flow for each nitinol tube, one needs to consider the tradeoff of losing the strength of the hexagon steel loading head wall when increasing the insulation layer thickness. Therefore, adding a coating/insulation layer is not the ultimate solution for the loading heads. The next design can fully solve this issue, but has more implementation challenges. 


\subsection{Decoupling Design for Loading Head}

To further reduce the impact from the loading head dead thermal mass, two more innovative designs are proposed which aim to eliminate any HTF contact with the loading head metal surfaces. Both designs use smaller plastic tubes for the HTF flow, where the plastic tubes are inserted inside either the loading plate or the loading head metal part. The plastic tubes' OD is supposed to be smaller than the ID of the HTF holes within the loading head. Since the HTF only flows inside those plastic tubes and the loading heads are only for compression, the design concept developed here is also known as a decoupling design for loading heads. In addition, using smaller plastic tubes also reduce the dead thermal mass of the HTF itself.

The first approach following this decoupling concept is shown in Figure 5, which does not have loading heads. Instead, the two loading plates originally in contact with the loading heads compress the nitinol tubes directly. It should be noted that there are holes on both loading plates to allow those small plastic tubes to be inserted inside the nitinol tubes.

Figure 6 illustrates the second approach. By using less rigid thermoplastic tubes, such as polyether-ether-ketone (PEEK) tubes, this decoupling concept can be applied to the original loading head directly. The thermoplastic tubes have a $90^{\circ}$ bend inside the loading head. The outside of the loading head is sealed by a distributor against the external HTF loop fitting, and rubber plugs are used to seal the other side from the nitinol tubes.

From a modeling perspective, there is no difference between the two approaches except the HTF thermal mass inside the plastic tubes. It is assumed that the plastic tubes are adiabatic from the loading head metal part, since there is a thin air gap in between. Therefore, the dead thermal mass of the metal loading head is totally reduced to zero in the model. Furthermore, the HTF thermal mass inside the loading head is also reduced accordingly. 


\subsection{Tube-in-tube and Rod-in-tube Designs}

The previous concepts aim to reduce the dead thermal mass of metal parts and part of the HTF. However, the major HTF thermal mass is inside the nitinol tubes. One way to achieve this goal is to add internal insertion nitinol tubes/rods inside the original nitinol tubes, as shown in Figure 7. Figure 7 (a) shows the tube-in-tube design, where the HTF (water) only flows between the inner small insertion nitinol tubes and the external original nitinol tube. The inner tubes are sealed on both ends so that there is no HTF flowing within them. The only difference between Figure 7 (a) and Figure 7 (b) is the change from inner smaller tubes to rods. Compared with the baseline scenario where there are no insertion tubes/rods, the new designs shown in Figure 7 not only reduce the HTF thermal mass, but also increase the ratio between the nitinol heat transfer area and the nitinol volume. A higher ratio results in higher heat transfer area between HTF and nitinol so that more cooling can be transferred in a certain time frame, or heat transfer can be accomplished within a shorter duration of time. As will be shown from the results, this ratio significantly enhances the time constant related to the heat transfer dynamics.

To model the change of fluid thermal mass as well as the surface to volume ratio, the following parameters are updated accordingly.

$$
\begin{aligned}
& A_{H T F}=\frac{\pi}{4}\left[I D^{2}-N \cdot O D_{\text {inner }}{ }^{2}\right] \\
& \mathrm{d} A_{H T}=\pi\left[I D+N \cdot O D_{\text {inner }}\right] \cdot \mathrm{d} x \\
& \mathrm{~d} V_{\text {nitinol }}=\frac{\pi}{4}\left[\left(O D^{2}-I D^{2}\right)+N \cdot\left(O D_{\text {inner }}{ }^{2}-I D_{\text {inner }}{ }^{2}\right)\right] \cdot \mathrm{d} x \\
& r a=\frac{\mathrm{d} A_{H T}}{\mathrm{~d} V_{\text {nitinol }}}=\frac{4\left[I D+N \cdot \text { OD }_{\text {inner }}\right]}{\left[\left(O D^{2}-I D^{2}\right)+N \cdot\left(O D_{\text {inner }}^{2}-I D_{\text {inner }}{ }^{2}\right)\right]}
\end{aligned}
$$




$$
\begin{aligned}
& N_{\text {nitinol }} \cdot d V_{\text {nitinol }}=N_{\text {nitinol }, b s} \cdot d V_{\text {nitinol }, b s} \\
& N_{\text {nitinol }}\left[\left(O D^{2}-I D^{2}\right)+N \cdot\left(O D_{\text {inner }}^{2}-I D_{\text {inner }}^{2}\right)\right]=N_{\text {nitinol }, b s} \cdot\left(O D^{2}-I D^{2}\right)
\end{aligned}
$$

Eq. (9) evaluates the reduced HTF cross section area to the flow direction, where $N$ denotes the insertion nitinol tubes/rods quantity. Eq. (10) represents the infinitesimal heat transfer area along the flow direction. The corresponding nitinol volume in contact with infinitesimal HTF is calculated by Eq. (11). Based on Eqs. (10-11), the surface to volume ratio is computed from Eq. (12). When adding multiple small nitinol tubes/rods to the original external nitinol tube, the nitinol total volume or mass increases, and therefore cannot compare to the baseline scenario directly, unless the total volume or mass of the nitinol is kept constant by Eq. (13). Here, it is assumed that the nitinol tubes length is also fixed. $N_{\text {nitinol }}$ is the quantity of external nitinol tubes, and $N$ is the quantity of smaller insertion tubes/rods within each external nitinol tube.

All the above mentioned design updates were integrated into the original baseline transient model developed in the previous study (Qian et al., 2014). The model was solved using Simulink ode3 solver with fixed time step of 0.002 seconds (Simulink, 2014).

\subsection{Model Validation}

To make the previously developed physics based model (Qian et al., 2015b) and the modified physics based model in this study more convincing, the modeling results were validated with the measured data using our first compressive thermoelastic cooling prototype developed. More details of the test facility set up and the prototype functioning details are introduced by Qian et al. (2015c). The thermocouples were calibrated to have a $0.2 \mathrm{~K}$ uncertainty. Figure 8 (a) describes the nitinol tubes bed temperature measurement details, where the inlet and outlet water temperatures were measured in stream. The temperature difference plotted in (b) and (c) were the temperature difference between the outlet temperature and the inlet temperature. It should be noted that this water temperature difference is not the system temperature lift. Figure 8 (b) shows the modeling versus simulation result, for a seven tubes bed with PEEK tubes under 3\% strain 
tested under $10 \mathrm{~g} / \mathrm{s}$. The water flow rate was constant during the entire testing, and the compression lasted 1.5 seconds. The dynamic response of the water temperature difference fits well and the accumulated energy delivered over the process was within $5 \%$. The maximum temperature difference peak was $2.4 \mathrm{~K}$ in this case with the help of the PEEK tubes. Figure 8 (c) compares the modeling versus simulation result during a specific test, for the same seven tubes bed without PEEK tubes under 3\% strain. The test was conducted when the compression, the heat transfer and the heat recovery duration were set to be 1.5 seconds, 8 seconds, and 25 seconds, respectively (referring to Figure 1 for more cycle details). The flow rate was $10 \mathrm{~g} / \mathrm{s}$ during the heat transfer stage and $4 \mathrm{~g} / \mathrm{s}$ during the heat recovery stage. This flow rates difference was also the reason leading to the different "slopes" of the temperature curve in Figure 8 (c). The data in Figure 8 (c) had a slow sampling rate, i.e. one data per second, which had less accuracy when compared with Figure 8 (b). The overall trend of the measured data fitted with the simulation result still well, and the overall energy balance over the heat transfer process was less than $7 \%$. The maximum temperature peak in this case was $1.8 \mathrm{~K}$, which was $0.6 \mathrm{~K}$ less than that of Figure 8 (b). The match of dynamic response between simulation and experiment data still make the model convincing and useful for optimization study. In addition, the temperature peak difference between Figures $8(\mathrm{~b})$ and $8(\mathrm{c})$ is already an evidence that the PEEK tubes design did function as expected.

\section{Multi-objective Optimization Problem}

To further enhance the system performance beyond the proposed novel designs, system operating variables such as cycle frequency, heat recovery duration, and flow rates can be optimized. These variables considerably affect the heat transfer loss identified in Figure 2. The objective is to maximize the cooling capacity, as well as COP. Therefore, a multi-objective optimization problem needs to be formulated and solved. The baseline design for the optimization problem is the best design achieved using the proposed novel designs. 
The formulation of the multi-objective optimization problem is shown in Table 2. The two objectives are maximizing both the cooling capacity and COP, which are conflicting with each other. The optimization design variables have the most significant impact on the system performance, which were discussed in a previous parametric study (Qian et al., 2015b). Heat transfer fluid and heat recovery fluid velocities influence the transient time constant directly, which are the first two design variables. The cycle frequency has a tradeoff between COP and cooling capacity since a slower cycle enhances the heat transfer and heat recovery, but simultaneously reduces the cooling capacity. The fourth design variable is the heat recovery duration coefficient $t^{*}$, which is a non-dimensional number determining the heat recovery process duration. This parameter was developed in the previous study (Qian et al., 2015a), and was shown that $t^{*}$ should be within $1.1-1.3$. The fifth design variable is the heat recovery pipe length, which is a key parameter contributing to the heat recovery efficiency as well as the system performance. The last design variable is the quantity of nitinol tubes in each bed. Since the total volume of the nitinol should be fixed to ensure a fair comparison, the first equality constraint shown in Eq. (14) (in Table 2) determines the length of each nitinol tube and insertion tubes/rods. The second constraint in Eq. (15) (in Table 2) was first proposed in the heat recovery study (Qian et al., 2015a) based on the physics of the counter-flow heat recovery process. The third constraint in Eq. (16) (in Table 2) is to have all systems operating under the temperature lift of $10 \mathrm{~K}$. Again, the baseline system for the optimization problem already included the proposed novel design concepts, which are tubes' holders' insulation, the decoupling loading head design, and seven insertion nitinol tubes in each original nitinol tube.

Multi-objective genetic algorithm (MOGA) from Matlab ${ }^{\mathrm{TM}}$ was used to solve the problem (MathWorks, 2014). The population size was chosen to be 90. Tournament, crossover fraction, migration fraction, and Pareto front population fraction were set to be 2, 0.8, 0.2 and 0.35 , respectively. The maximum generation was set to be 200 as a termination criterion. Figure 9 
illustrates the problem solving procedure, which started from the problem initialization setup. The iteration optimization process, called the Simulink model for each design candidate, was developed in the previous study and modified with the improvement designs introduced in this study. The system COP and cooling capacity were computed by data reduction from the temperature profiles as results from the Simulink model. The optimization process is terminated, either by the changing of fitness functions in population or by maximum iteration. Pareto sorting generates the Pareto frontier among the last iteration population. The optimization was repeated four times to enhance the confidence from the Pareto frontier. Finally, we applied the SMARTS decision making method (Edwards and Barron, 1994) to rank the Pareto front solutions according to our desired requirements and get the final solution, including the two objectives $\left(Q_{\mathrm{c}}\right.$ and $\left.\mathrm{COP}\right)$, the cycling frequency (measured by the cycle duration), and the simplicity of the system (measured by the nitinol tubes number $N$ ). A shorter cycle duration is corresponding to a higher operating frequency, and has the potential to reduce the nitinol mass required and the cost associated with it. Less nitinol tubes means less force is needed with the smaller cross section area, and consequently simpler compression system and supporting frame is needed.

\section{Results and Discussions}

In this section, the results using novel designs are discussed first, followed by the enhancement on the novel designs using optimization. Last, the potential of thermoelastic cooling using the improvement results from this study and the updated loss analysis chart are analyzed.

\subsection{Performance Improvements with Novel Designs}

Figure 10 is an overview of the performance enhancement results with the novel designs, which plots the maximum temperature lift achievable with the five different designs proposed earlier. Here, dry loading head refers to the decoupling design for the loading head, since there is 
no more HTF in direct contact with the loading head. The reason why COP or cooling capacity was not used as an index here is due to the fact that the baseline could not reach the $10 \mathrm{~K}$ temperature lift. Nevertheless, the system maximum temperature lift is still a fair index to compare. The red bar on the left is the baseline temperature lift, which is $6.6 \mathrm{~K}$. When adding the insulation layer to the tubes' holders as described in Section 2.1, there is an improvement of $0.5 \mathrm{~K}$ when compared with the baseline. Loading head insulation layer results in much higher enhancement, since the HTF is in direct contact with the loading head. Compared to the loading head, even with the much higher thermal mass, the tubes' holders did not contribute much to the loss initially, since it is only in line contact with the nitinol tubes. The dry loading head design introduced in Section 2.3 adds an additional improvement of $4.3 \mathrm{~K}$ compared to the insulation layer in the loading head. This can be regarded as another important argument about the contribution of loading head to the loss. The next stage improvement is the most significant step towards achieving a better performance. A $9.2 \mathrm{~K}$ temperature lift enhancement was achieved by applying the rod-in-tube design, due to the simultaneous reduction in HTF thermal mass, as well as higher heat transfer surface to volume ratio for nitinol. Another $2.9 \mathrm{~K}$ improvement can be achieved by switching the rods to tubes without flowing any HTF inside. Note that for a fair comparison, the nitinol volume and mass was kept constant, as shown in Eq. (13).

The role of insulating the loading head is discussed in more detail in Figure 11. The few points with the capacity of zero were due to insufficient maximum achievable temperature lift. As expected, increasing the insulation layer thickness reduced the heat transfer between the HTF and the metal loading head, and the associated losses as well. Eventually, the insulation approaches the critical thickness, which is around $2 \mathrm{~mm}$ from Figure 11. By applying the insulation layer, the maximum improvement for $\mathrm{COP}$ is from 0 to 0.5 .

Figure 12 shows the details when the dry loading head concept was applied as introduced in Section 2.3. The solid curve corresponds to the case where both the loading head and the tubes' 
holders were insulated, while the dry loading head design corresponds to the dashed curve. The first observation is that the solid curve has more temperature oscillation amplitude. Due to the thermal mass of the loading head, heat was absorbed from the HTF during the heat rejection process from 660 to 668 seconds and causing the additional temperature drop. The temperature oscillation was delayed in a solid line compared to the dashed line. This increase in the time constant was also due to the loading head thermal mass. In addition, when compared to the solid line, the dry loading head design had a higher fluid temperature during the heat rejection process from 660 to 668 seconds, and less fluid temperature during the cooling delivery process from 670 to 678 seconds. Therefore, more heating as well as more cooling is achieved using the two heat transfer processes.

When both the tubes' holders' insulation and the decoupling loading head design were applied, the role of tube-in-tube and rod-in-tube designs can be studied. Inserting small nitinol rods or tubes helps to reduce the HTF thermal mass inside the regular nitinol tube, as well as increasing the nitinol heat transfer surface to volume ratio. Figure 13 plots the performance enhancement of several different candidates using the nitinol heat transfer area to volume ratio as the control variable. Figure 13 illustrates that the performance increased monotonically with the nitinol heat transfer area to volume ratio. A higher nitinol heat transfer area to volume ratio means smaller heat transfer time constant, or equivalently, more heating/cooling transferred per unit mass per unit time. Whenever any rod or small tubes were inserted in a regular tube, the nitinol heat transfer area to volume ratio is increased. Therefore, adding smaller tubes or rods enhances the capacity and COP. Also, inserting small tubes has the same surface heat transfer area as the small rods but with less volume per regular tube and, therefore, has a higher heat transfer surface to volume ratio. The best two points on Figure 13 for tube-in-tube and rod-in-tube designs are corresponding to the enhancement cases plotted in Figure 10. 


\subsection{Multi-objective Optimization Results}

The optimization routine described in Figure 9 terminated after the $115^{\text {th }}$ generation, when the relative change in fitness function evaluation was less than $0.01 \%$. To visualize the convergence of the solution, Figure 14 shows how a few indices vary between generations. Both the COP and cooling capacity were normalized to the maximum COP or capacity evaluated. Figure 14 (a) shows the average indices among the entire population for each generation, and both of them oscillated due to the stochastic nature of genetic algorithm. The average indices will not converge to 1 , so a well-developed spread can be guaranteed. On the contrary, both the maximum COP and capacity almost converged to 1 . Again, the deviation of capacity from 1 is due to the random nature of genetic algorithm.

Figure 15 plots all the evaluated candidates, the Pareto front solutions set, and the final solution with the SMARTS decision making procedure. It was the best Pareto front out of four runs. The wide spread of the Pareto solutions provides the designers enough design candidates to choose from for the final design. The Pareto front contained 320 final solutions out of the 10,350 evaluated candidates. All the blue diamonds (evaluated candidates) consist of a triangle region, bounded by the $(0,0)$ origin, the maximum COP point, and the maximum capacity point. This triangle domain is determined by the design variables' upper and lower bounds, specified in Table 2. When the upper and lower bounds are further relaxed, the triangle domain spans more accordingly. The limiting case would be relaxing all the design variables to be no less than zero. In that case, we can expect the Pareto front to extend all the way to COP axis when the cycle duration approaches infinity, leading to almost zero capacity but finite COP. Comparing the Pareto front solutions to the baseline case with all the novel designs specified in Figure 10, optimization can further enhance the system performance by partially reducing the cyclic loss and reducing the heat transfer loss. The maximum COP point reached a COP of 4.1, corresponding to almost $31 \%$ COP enhancement but had a capacity reduction tradeoff. If the cooling capacity 
remained constant, the COP enhancement was 9.3\%. The capacity enhancement was $19.1 \%$ when the COP was fixed. The maximum capacity point reached $184 \mathrm{~W}$, corresponding to a $20.5 \%$ capacity enhancement. One can expect to reach a higher capacity than this if the lower bound of cycle duration $t_{\mathrm{cyc}}$ can be relaxed, i.e. cycling faster. A detailed quantitative comparison from the baseline scenario with the tube-in-tube design shown as the highest COP/capacity point from Figure 13 can be found in Table 3. Table 3 only shows four special points out of the 320 Pareto solutions from the multi-objective optimization. Compared to the variables' bounds specified in Table 2, we can conclude that a slower cycle with less HR velocity and fewer, albeit longer, nitinol tubes are preferred for maximizing the COP perspective.

A compromise is needed to choose the final design solution. Table 4 presents the decision making procedure results using the SMARTS method as aforementioned. The four attributes are the COP, cooling capacity, the frequency and the simplicity, where the COP is considered to be the most important attribute. Each of these four attributes were normalized to the corresponding maximum values and minimum values, ranging from zero to one. All 320 Pareto solutions were considered as alternatives listed on the decision table. The four weights were assigned according to Edwards and Barron (1994). The processed result had the top ranking value of 0.60 , where the average and standard deviation among 320 alternatives were 0.53 and 0.06 , respectively. As shown in Table 4 and Figure 15, the final solution is laying in the middle of the Pareto spread, as a tradeoff between COP and cooling capacity. Since COP has higher weight coefficient, the solution is closer to the maximum COP limit. The third attribute prefers higher capacity, and the fourth attribute prefers higher COP. The final solution will be implemented and validated by the experiment set up in the future study.

\subsection{Outlook}

Our ultimate goal is to reduce the losses at all stages by $50 \%$, as discussed in the previous study (Qian et al., 2015b). Figure 2 in this study establishes the baseline; the system COP was 0 
due to the metal loading head and tubes' holders' thermal mass in the real prototype setup. With all the methods introduced in this study, we could successfully reduce the fourth and fifth losses, as shown in Figure 16. The fifth stage loss was reduced 73\%, with a COP of 3.4, considering the pump power consumption to be $20 \%$ of the driving system's work, as a result of including the novel designs and partially due to optimization. The fourth stage loss had a $37 \%$ reduction as a result of the optimization. The long term goal in Figure 16 also requires a substantial reduction in the second stage loss, which is from the inefficiency of the current Brayton cycle design using adiabatic loading. With a hybrid cycle combining Stirling (isothermal loading) and Brayton cycle (adiabatic loading), the goal of reaching COP of 7.7 could potentially be achievable. This will be a future study.

\section{Conclusions}

This study discussed multiple ways to improve the performance of a compressive thermoelastic cooling system, as guidelines to real prototypes under development. Several novel design options were investigated which reduced the cyclic loss from the thermal mass of the loading head and tubes' holders. These options include a thin film coating and insulating layer for both the tubes' holders and the loading head, two different decoupling designs for loading head, and finally the tube-in-tube or rod-in-tube design. The performance improvements were evaluated based on the previously developed dynamic model with the modifications proposed in this study. It was found that the decoupling design for loading head paired with the tube-in-tube design resulted in the most significant improvement. In addition, multi-objective optimization was used to further enhance the system COP, as well as capacity. It was found that the maximum temperature lift increased from $6.6 \mathrm{~K}$ to $27.8 \mathrm{~K}$ when applying the proposed novel designs. The cooling capacity can be enhanced from $0 \mathrm{~W}$ to $152 \mathrm{~W}$ with the novel designs before optimization, and up to $184 \mathrm{~W}$ with optimization, both at $10 \mathrm{~K}$ water-water system temperature lift. The COP enhancement is from 0 to 3.1 before optimization, and up to 4.1 with optimization. From the 
losses perspective, the heat transfer loss was reduced $37 \%$, and the cyclic loss was reduced $73 \%$.

Future work on the performance enhancement will be focused on exploring the hybrid Brayton and Stirling cycle integration with thermoelastic cooling system.

\section{Acknowledgement}

The authors gratefully acknowledge the support of this effort from the U.S. DOE and the Center for Environmental Energy Engineering (CEEE) at the University of Maryland. This work was supported by DOE ARPA-E DEAR0000131.

\section{References}

Bahl, C., Engelbrecht, K., Eriksen, D., Lozano, J., Bjork, R., Geyti, J., Pryds, N., 2014. Development and experimental results from a $1 \mathrm{~kW}$ prototype AMR. Int. J. Refrigeration 37, 7883.

Bechtold, C., Chluba, C., Lima de Miranda, R., \& Quandt, E., 2012. High cyclic stability of the elastocaloric effect in sputtered TiNiCu shape memory films. Appl. Phys. Lett. 101, 091903.

Bonnot, E., Romero, R., Manosa, L., Vives, E., Planes, A., 2008. Elastocaloric effect associated with the Martensitic transition in shape-memory alloys. Phys. Rev. Lett. 100. DOI: 10.1103/PhysRevLett.100.125901.

Buehler, W., Gilfrich, J., Wiley, R., 1963. Effect of low temperature phase changes on the mechanical properties of alloys near composition TiNi. J. Appl. Phys. 34, 1475-1477.

Cui, J., Wu, Y., Muehlbauer, J., Hwang, Y., Radermacher, R., Fackler, S., et al., 2012. Demonstration of high efficiency elastocaloric cooling with large $\Delta \mathrm{T}$ using NiTi wires. Appl. Phys. Lett. 101. DOI: 10.1063/1.4746257.

Edwards, W. and Barron, F.H., 1994. SMARTS and SMARTER: Improved simple methods for multiattribute utility measurements, Organ. Behav. Hum. Dec. 60, 306-325. 
Fischer, S., Tomlinson, J., \& Hughes, P., 1994. Energy and Global Warming Impacts of Not-inKind and Next Generation CFC and HCFC Alternatives. Oak Ridge, USA.

Gerlach, D., 2009. Design concepts and development of elastomer heat engines/pumps. Proc. ASME IMECE, Lake Buena Vista, FL, 9, pp. 289-293.

Gu, H.M., Qian, X.S., Li, X.Y., Craven, B., Zhu, W.Y., Cheng, A.L., et al., 2013. A chip scale electrocaloric effect based cooling device. Appl. Phys. Lett. 102, 122904. DOI: 10.1063/1.4799283.

Jia, Y., Ju, Y.S., 2012. A solid-state refrigerator based on the electrocaloric effect. Appl. Phys. Lett. 100, 242901. DOI: 10.1063/1.4729038.

Jacobs, S., Auringer, J., Boeder, A., Chell, J., Komorowski, L., Leonard, J., Zimm, C., 2014. The performance of a large-scale rotary magnetic refrigerator. Int. J. Refrigeration 37, 84-91.

Lyon, R., Wang, D., Farris, R., \& MacKnight, W., 1984. Polyurethane-urea elastomers as working substances in rubber heat engines. J. Appl. Poly. Sci. 29, 2857-2872.

Manosa, L., Planes, A., Ortin, J., 1993. Entropy change of martensitic transformation in Cu-based shape-memory alloys. Phys. Rev. B 48, 3611-3619.

MathWorks, 2014. http://www.mathworks.com/help/gads/gamultiobj.html (Accessed on Nov $4^{\text {th }}$, 2014).

Miura, S., Moruta, Y., \& Nakanishi, N., 1975. Superelasticity and shape memory effect in Cu-Sn alloys. In J. Perkins, Shape Memory Effects in Alloys (pp. 389-405). New York, USA: Springer.

Nikitin, S., Myalikgulyev, G., Annaorazov, M., Tyurin, A., Myndyev, R., \& Akopyan, S., 1992. Giant elastocaloric effect in FeRh alloy. Phys. Lett. A 171, 234-236. 
Otsuka, K., Wayman, C.M., 1998. Shape memory materials. Cambridge University Press, Cambridge.

Picornell, C., Pons, J., Cesari, E., 2004. Stress-temperature relationship in compression mode in Cu-Al-Ni shape memory alloys. Mater. Trans. 45, 1679-1683.

Qian, S., Ling, J., Muehlbauer, J., Hwang, Y., Radermacher, R, 2015a. Study on high efficient heat recovery cycle for solid-state cooling - Part 1: theoretical analysis. Int. J. Refrigeration, In Press, Available online, doi:10.1016/j.ijrefrig.2015.03.023.

Qian, S., Ling, J., Hwang, Y., Radermacher, R., Takeuchi, I., 2015b. Thermodynamics cycle analysis of thermoelastic cooling and heat pump systems. Int. J. Refrigeration (Accepted).

Qian, S., Wu, Y., Ling, J., Muehlbauer, J., Hwang, Y., Takeuchi, I., et al., 2015c. Design, development and testing of a compressive thermoelastic cooling prototype. Submitted to the International Congress of Refrigeration 2015, Japan.

Qian, S., Ling, J., Hwang, Y., Radermacher, R., 2014. Dynamic Performance of a Compression Thermoelastic Cooling Air-Conditioner under Cyclic Operation Mode. International Refrigeration and Air Conditioning Conference, West Lafayette, IN.

Romero, R., \& Pelegrina, J., 2003. Change of entropy in the martensitic transformation and its dependence in Cu-based shape memory alloys. Mater. Sci. Eng. A 354, 243-250.

Saburi, T., 1998. Ti-Ni shape memory alloys. In K. Otsuka, \& C. Wayman, Shape Memory Materials (pp. 75-79). Cambridge, UK: Cambridge University Press.

Sarlah, A., Kitanovski, A., Poredos, A., Egolf, P.W., Sari, O., Gendre, F., et al., 2006. Static and rotating active magnetic regenerators with porous heat exchangers for magnetic cooling. Int. J. Refrigeration 29, 1332-1339. 
Sharp, J., Bierchenk, J., Lyon, H.B., 2006. Overview of solid-state thermoelectric refrigerators and possible applications to on-chip thermal management. Proc. IEEE 94, 1602-1612.

Simulink, 2014. http://www.mathworks.com/products/simulink/ (Accessed on Nov $\left.4^{\text {th }}, 2014\right)$.

Xiao, F., Fukuda, T., \& Kakeshita, T., 2013. Significant elastocaloric effect in a Fe-31.2Pd (at. \%) single crystal. Appl. Phys. Lett. 102, 161914.

Zimm, C., Boeder, A., Chell, J., Sternberg, A., Fujita, A., Fujieda, S., et al., 2006. Design and performance of a permanent-magnet rotary refrigerator. Int. J. Refrigeration 29, 1302-1306. 


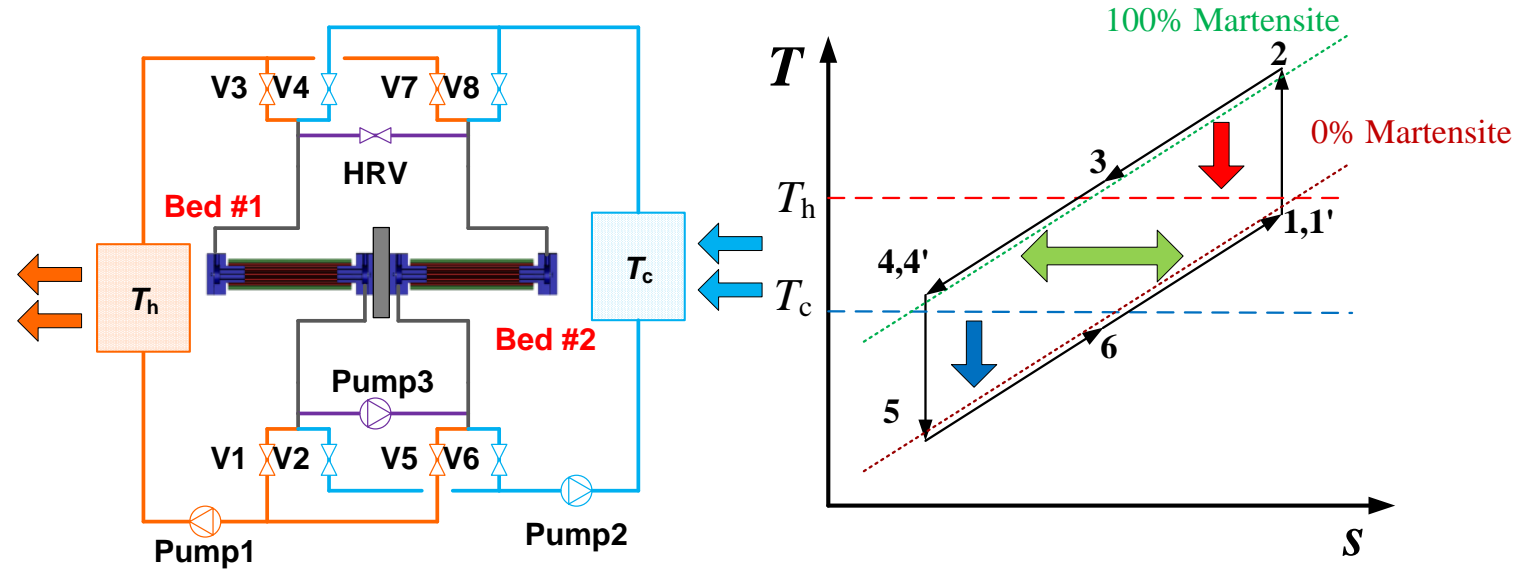

(a) Schematic of the designed thermoelastic cooling system

(b) Thermoelastic cooling cycle on a $T-s$ diagram

Figure 1: Thermoelastic cooling using SMA under compression mode. (Qian et al., 2015b) 

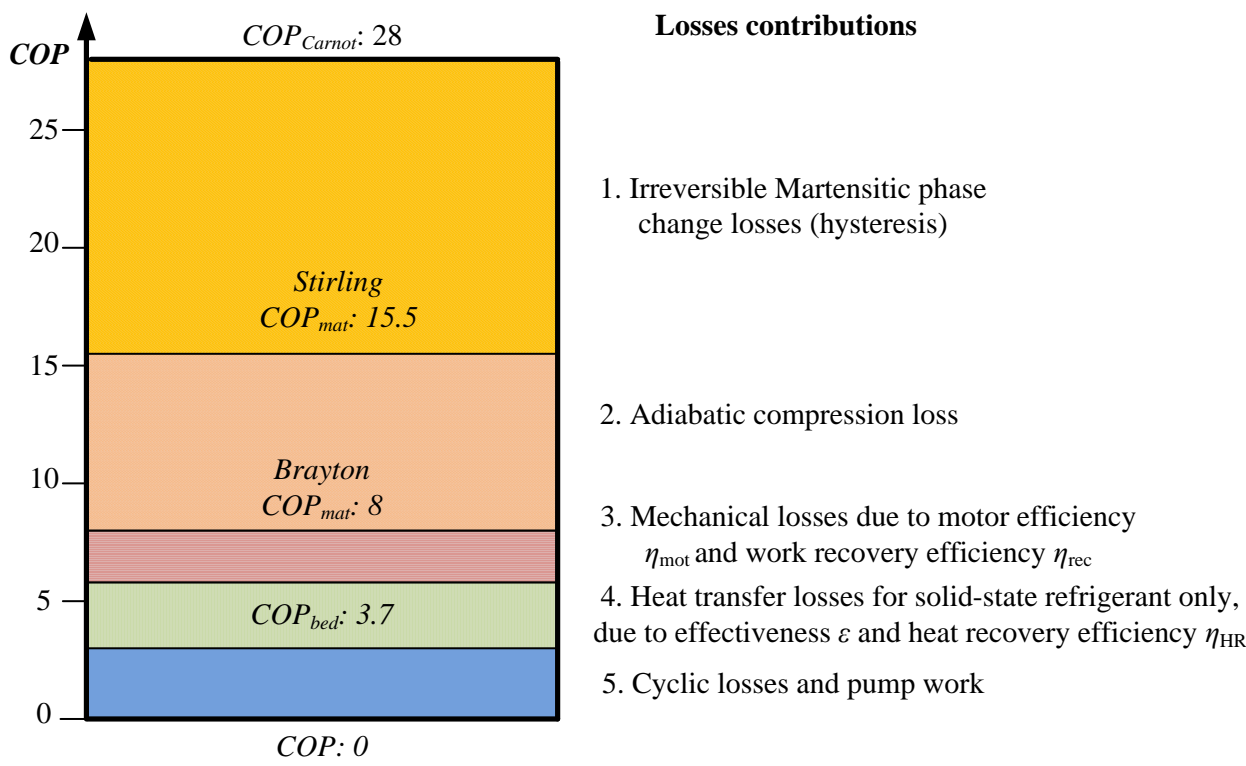

2. Adiabatic compression loss

3. Mechanical losses due to motor efficiency $\eta_{\text {mot }}$ and work recovery efficiency $\eta_{\text {rec }}$

4. Heat transfer losses for solid-state refrigerant only, due to effectiveness $\varepsilon$ and heat recovery efficiency $\eta_{\mathrm{HR}}$

5. Cyclic losses and pump work

Figure 2: Illustration of loss breakdown chart for a compressive thermoelastic cooling system baseline scenario operated under $10 \mathrm{~K}$ temperature lift (COP was zero because the maximum achievable temperature lift was 6.6 K). (Qian et al., 2015b) 


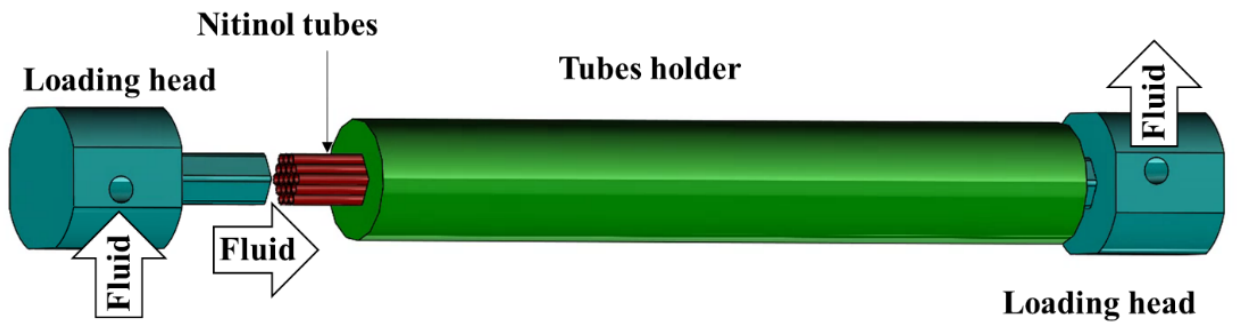

Figure 3: Drawing of the baseline/original design of the SMA bed assembly using nitinol tubes under compression mode. 


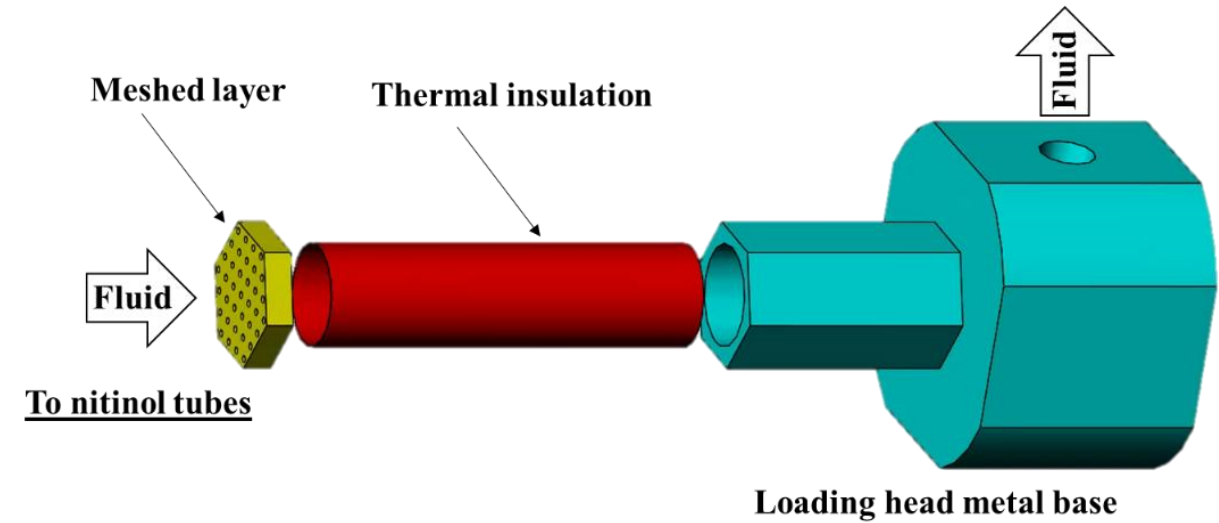

Figure 4: Illustration of the insulation layer design for loading head. 


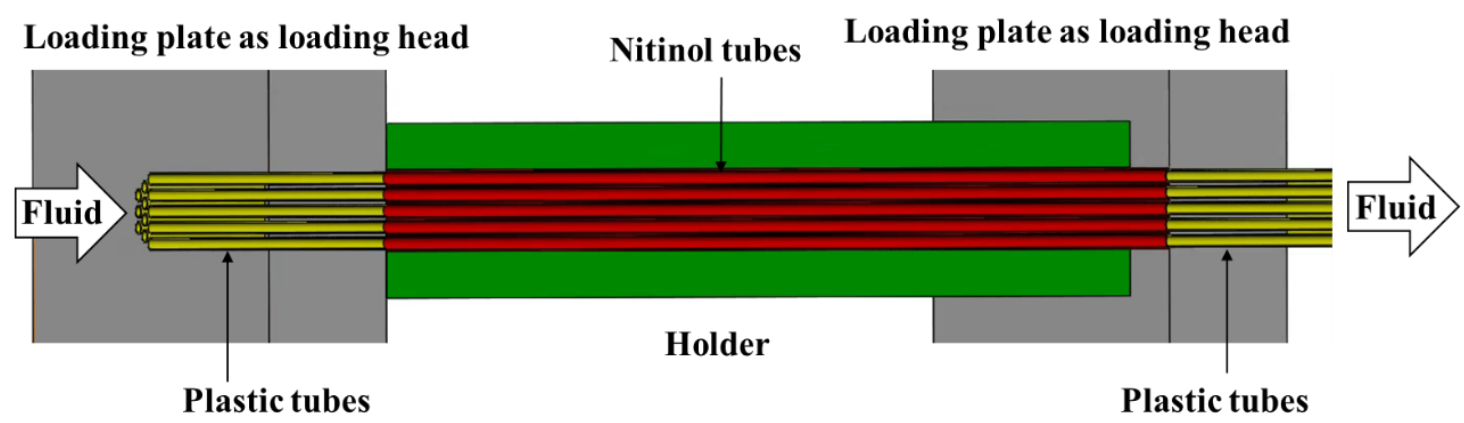

Figure 5: Illustration of the direct compression without loading head design. 


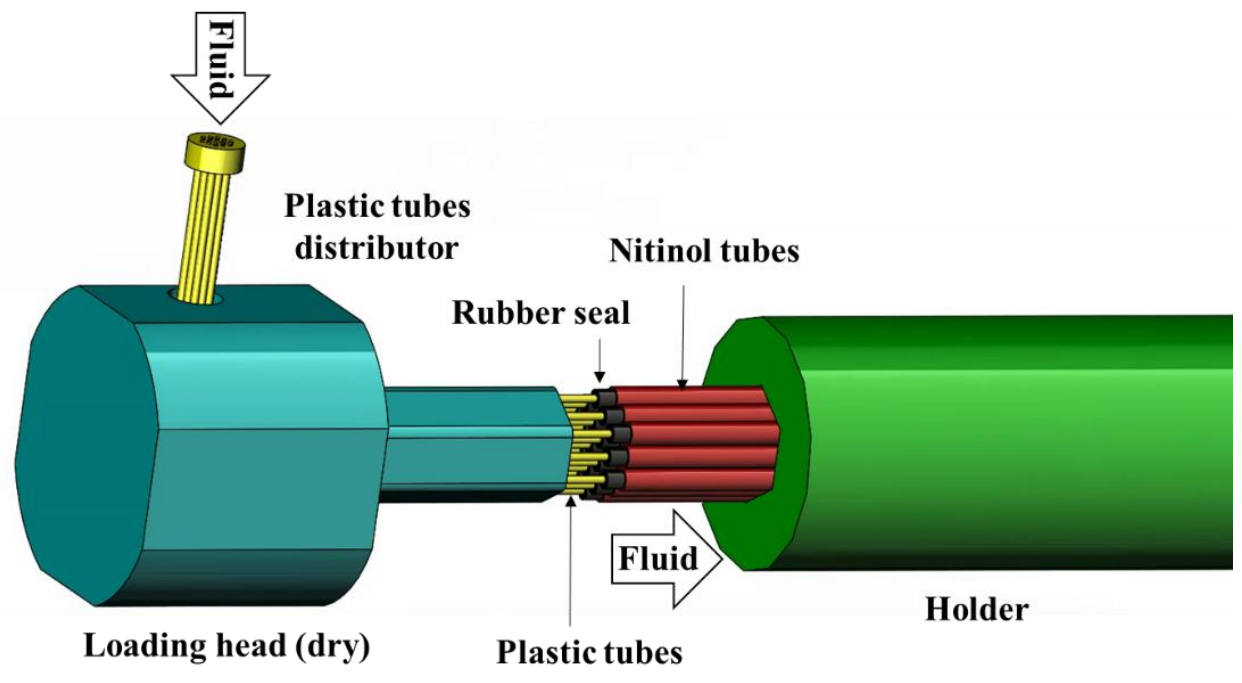

Figure 6: Illustration of the dry loading head design. 

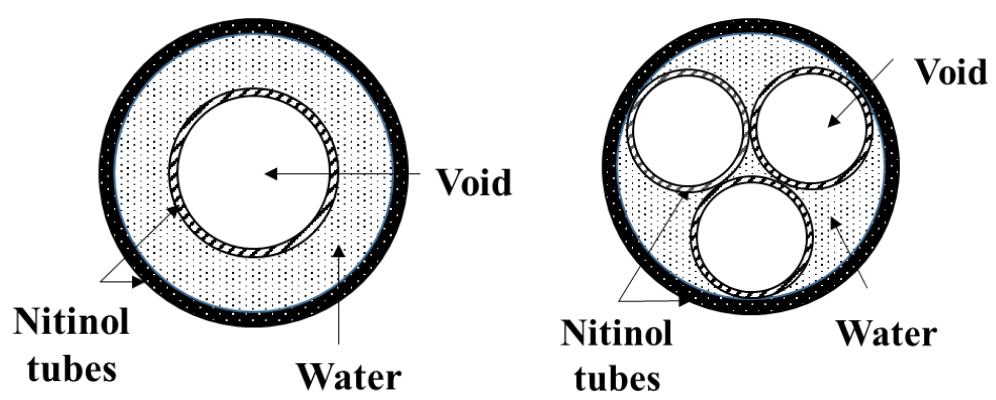

(a) Tube-in-tube design
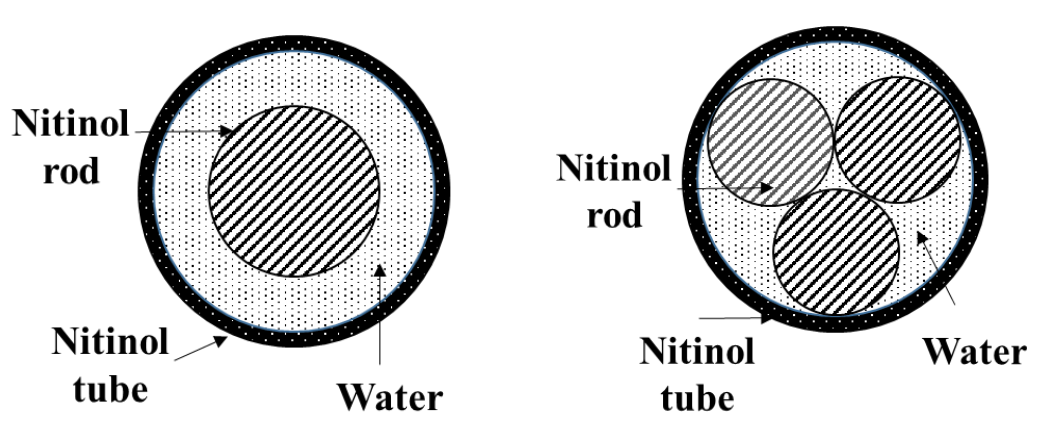

(b) Rod-in-tube design

Figure 7: Illustration of the tube-in-tube and rod-in-tube design using multiple small tubes or rods inside each regular nitinol tube. 


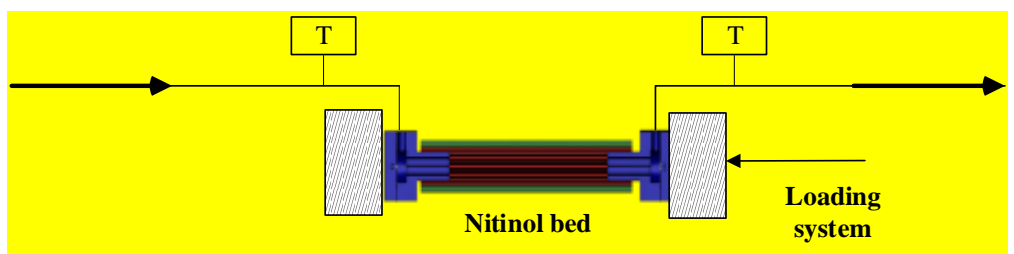

(a) Schematic of the nitinol tubes bed and temperature measurement test set up

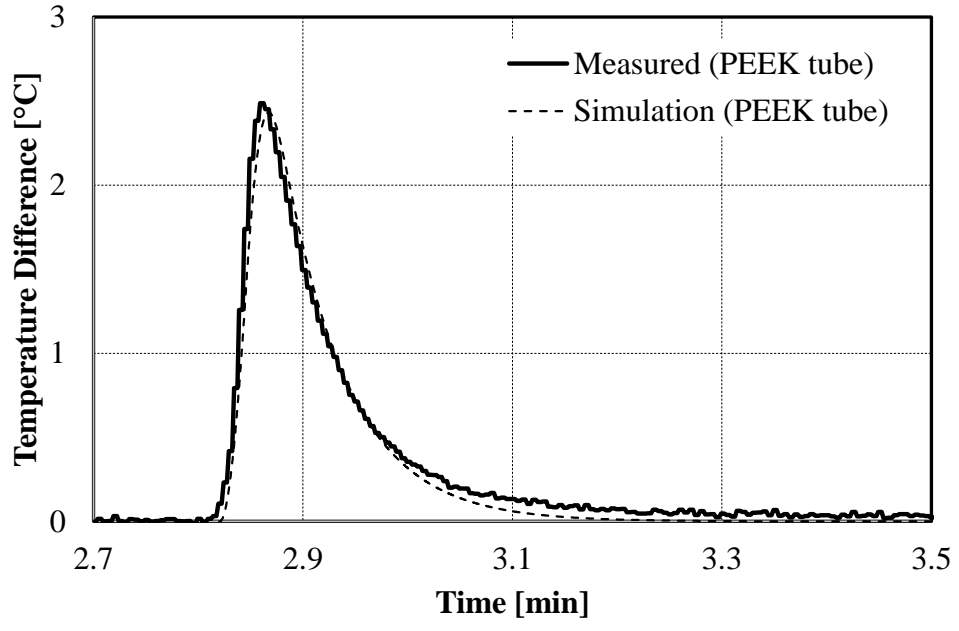

(b) Improved case: measured water temperature difference across a seven tubes nitinol bed with PEEK tubes under $10 \mathrm{~g} / \mathrm{s}$ flow rate for model validation

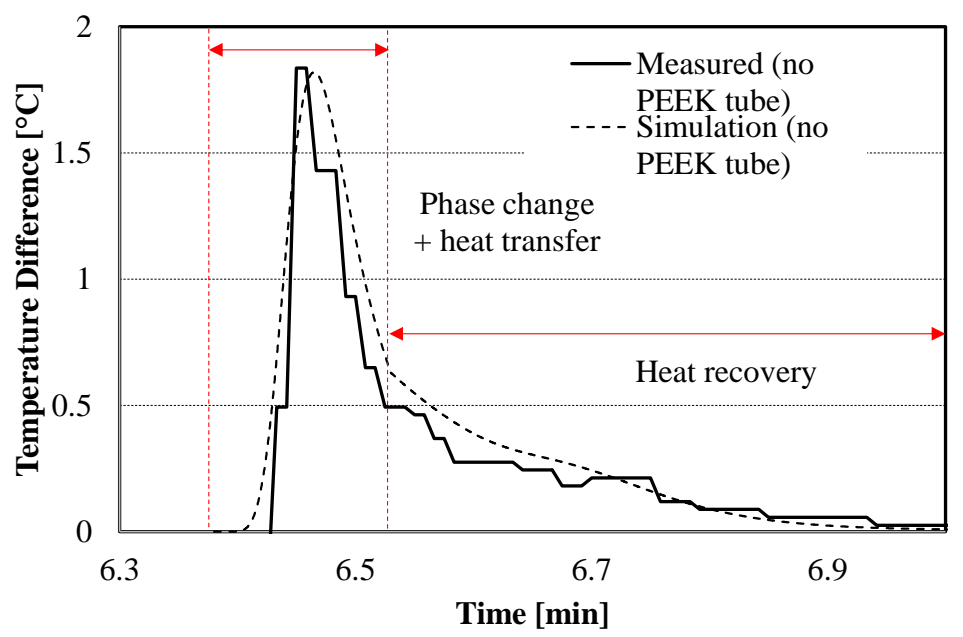

(c) Baseline: measured water temperature difference across a seven tubes nitinol bed with no PEEK tubes under $10 \mathrm{~g} / \mathrm{s}$ flow rate during system operation (including phase change, heat transfer and heat recovery stages introduced in Figure 1)

Figure 8: Illustration of a preliminary model validation using the nitinol beds temperature measurement and comparison of the PEEK tubes implementation. 


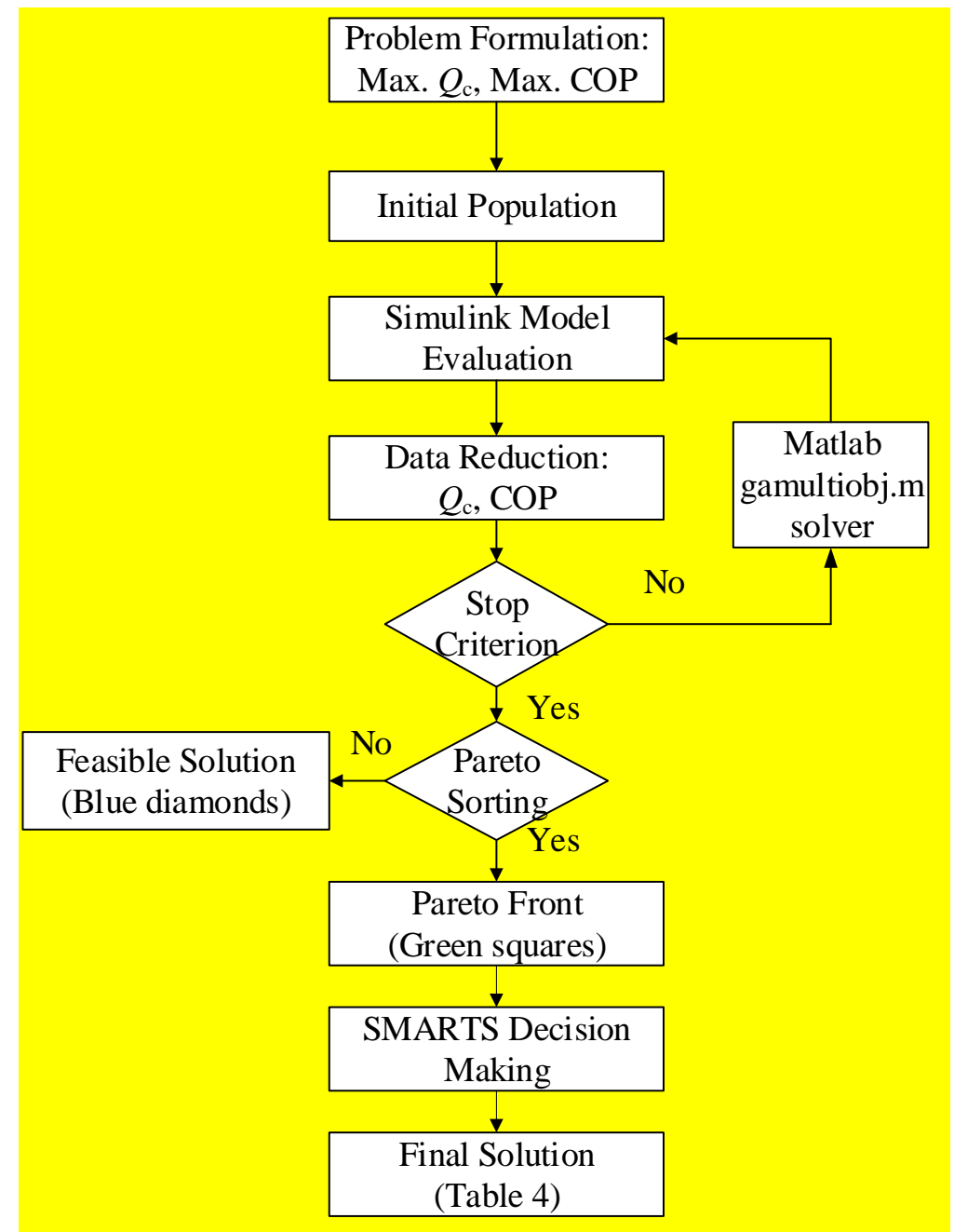

Figure 9: Flow chart of the multi-objective optimization problem solving procedure. 


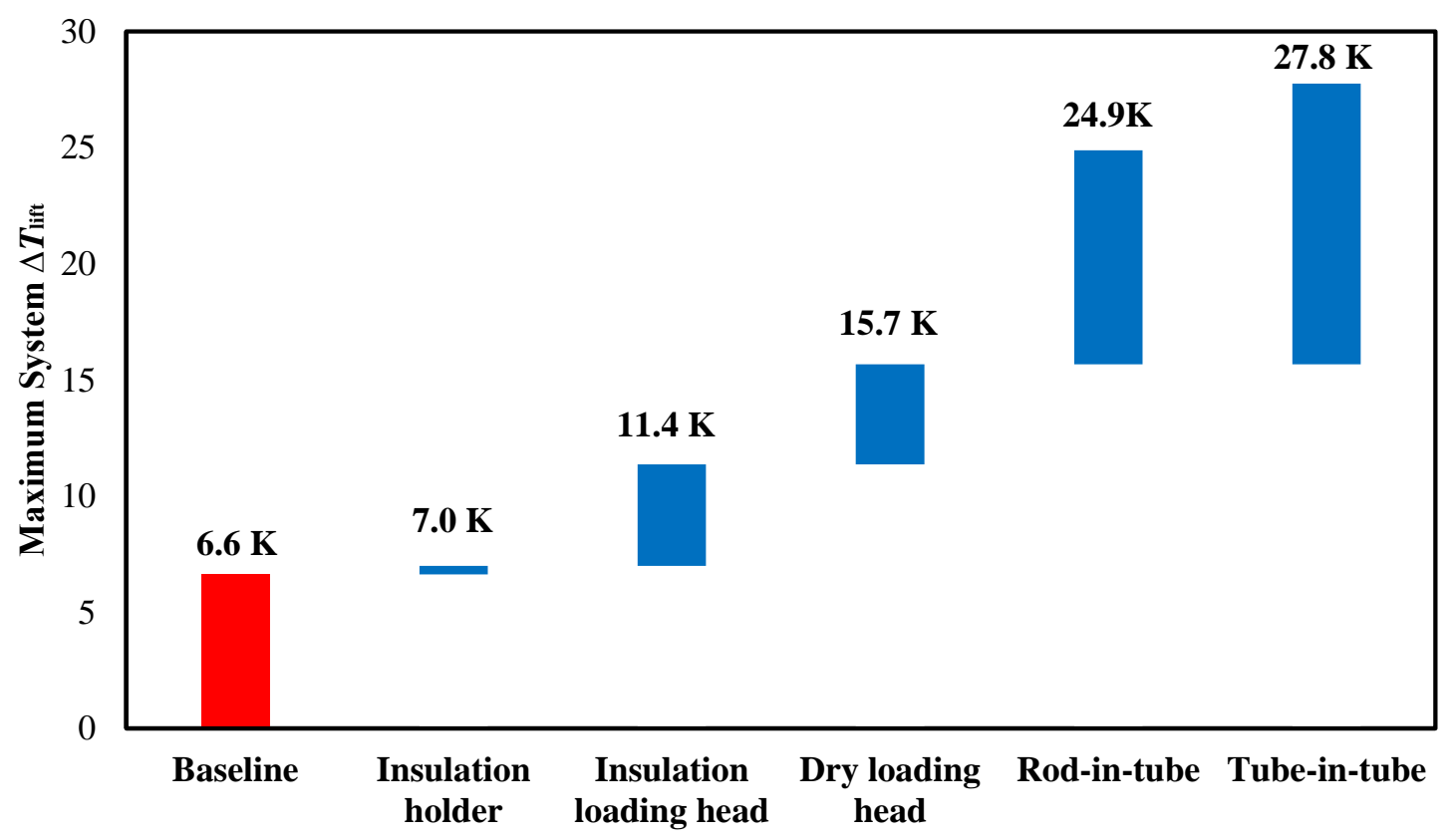

Figure 10: Summary of performance enhancement as results of novel designs. (all designs have the same nitinol volume and mass, $\Delta T_{\text {lift }}=10[\mathrm{~K}], u=0.8[\mathrm{~m} / \mathrm{s}], u_{\mathrm{HR}}=0.4[\mathrm{~m} / \mathrm{s}], t_{\mathrm{cyc}}=10$ [sec]) 


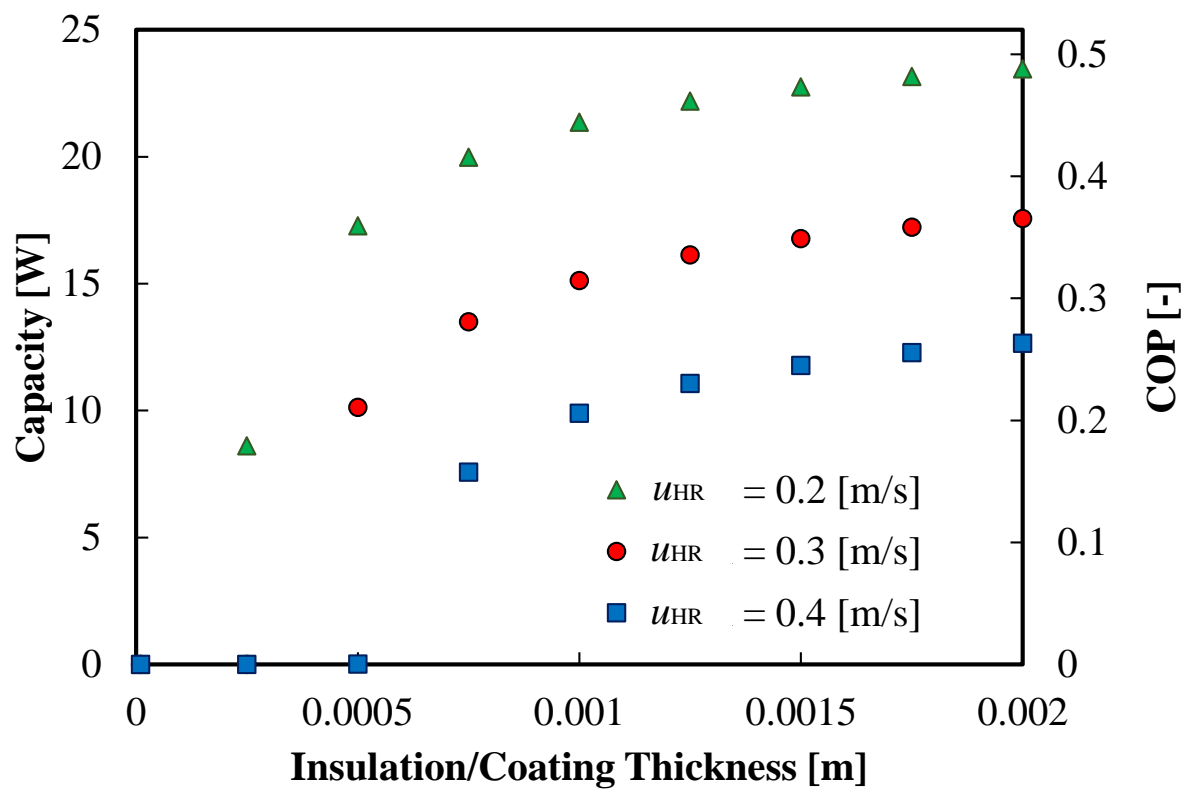

Figure 11: Capacity enhancement as a result of the coating/insulation layer design. $\left(\Delta T_{\text {lift }}=\right.$ $\left.10[\mathrm{~K}], u=0.8[\mathrm{~m} / \mathrm{s}], t_{\text {cyc }}=10[\mathrm{sec}]\right)$ 


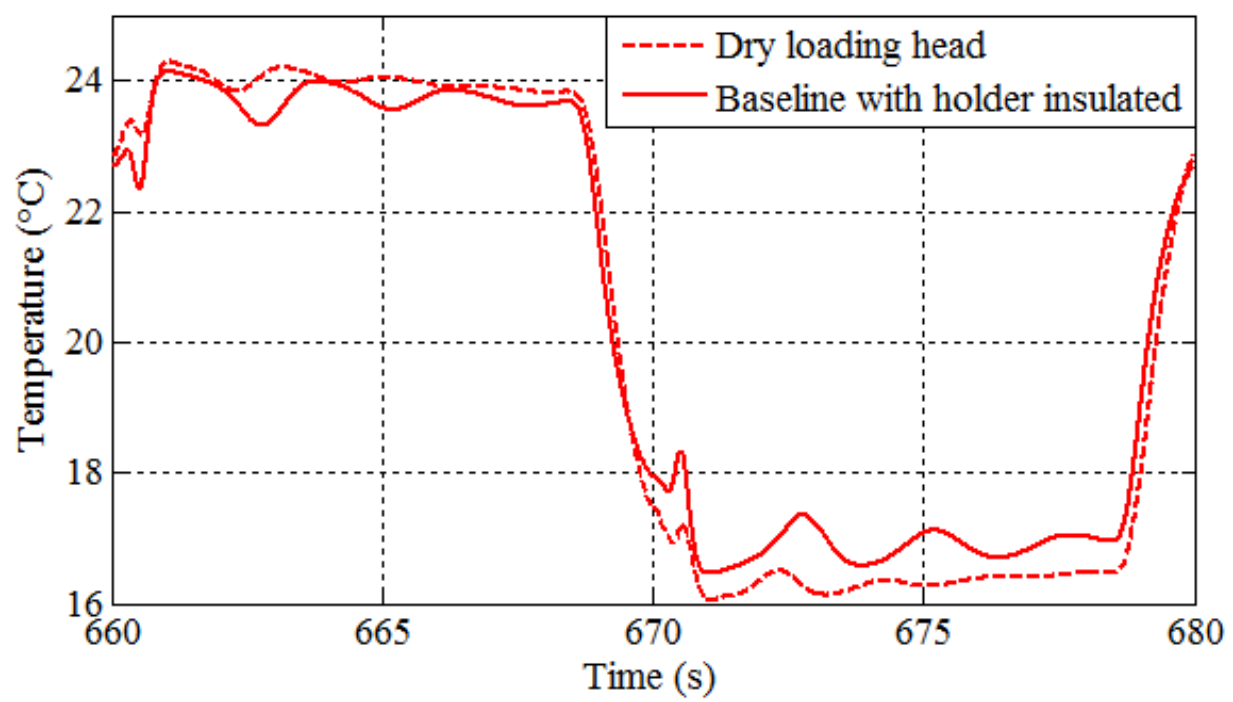

Figure 12: Illustration of capacity enhancement by applying plotting the exit fluid temperature of the outlet loading head using decoupling loading head design. $\left(\Delta T_{\text {lift }}=5[\mathrm{~K}]\right.$, $\left.u=0.8[\mathrm{~m} / \mathrm{s}], u_{\mathrm{HR}}=0.4[\mathrm{~m} / \mathrm{s}], t_{\mathrm{cyc}}=10[\mathrm{sec}]\right)$ 


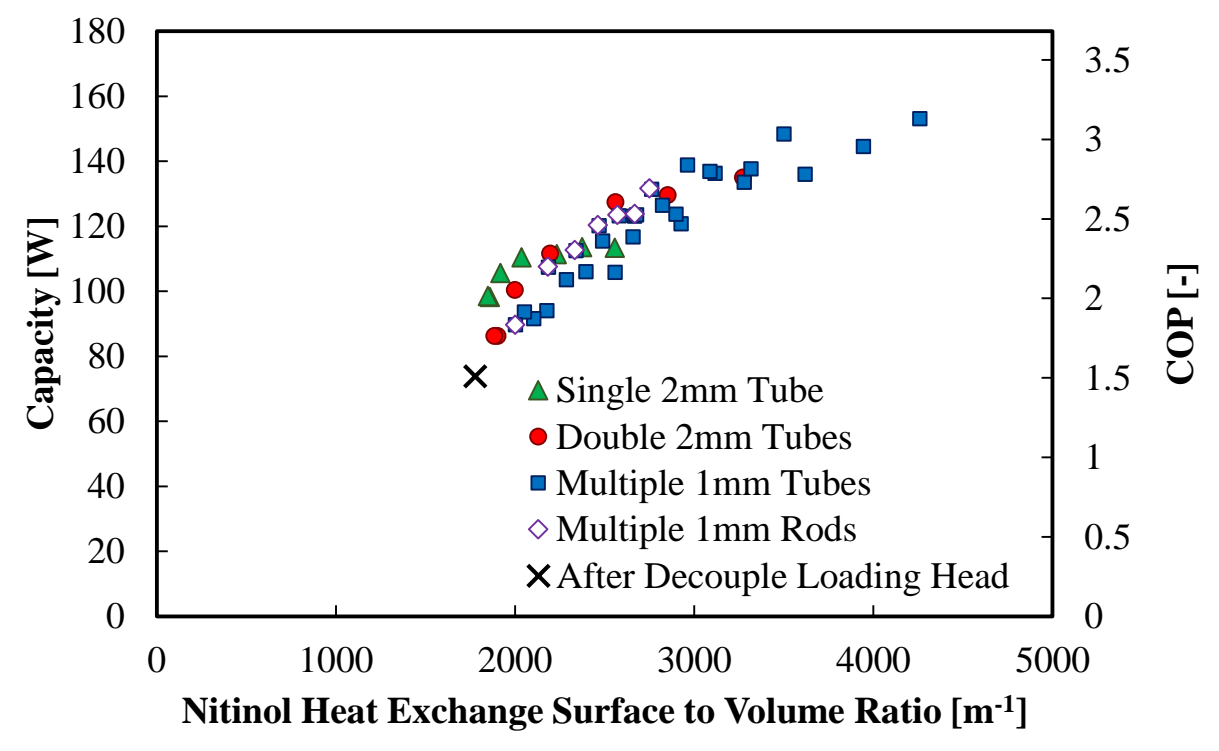

Figure 13: Capacity enhancement as a result of the tube-in-tube and rod-in-tube design. $\left(\Delta T_{\text {lift }}=10[\mathrm{~K}], u=0.8[\mathrm{~m} / \mathrm{s}], u_{\mathrm{HR}}=0.4[\mathrm{~m} / \mathrm{s}], t_{\mathrm{cyc}}=10[\mathrm{sec}]\right)$ 


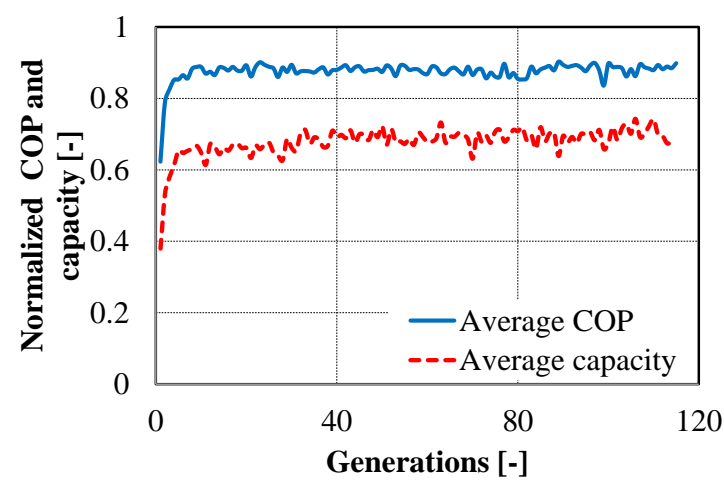

(a) Average COP and capacity among the entire population for each generation (normalized to the maximum values)

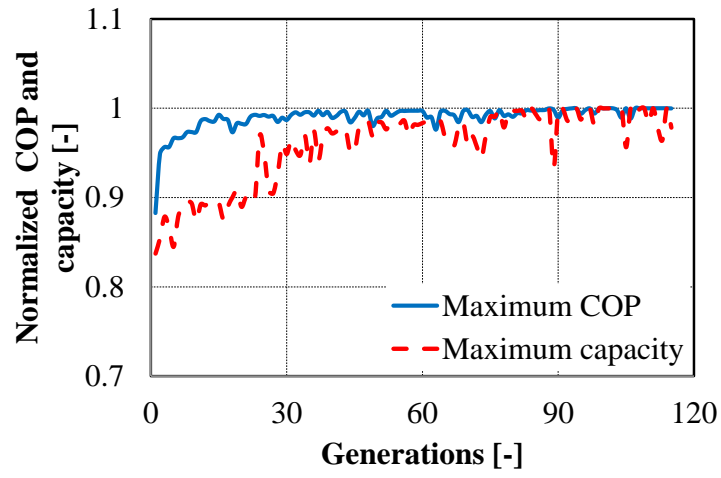

(b) Maximum COP and capacity among the entire population for each generation (normalized to the maximum values)

Figure 14: Solutions over iterations and illustration of convergence. 


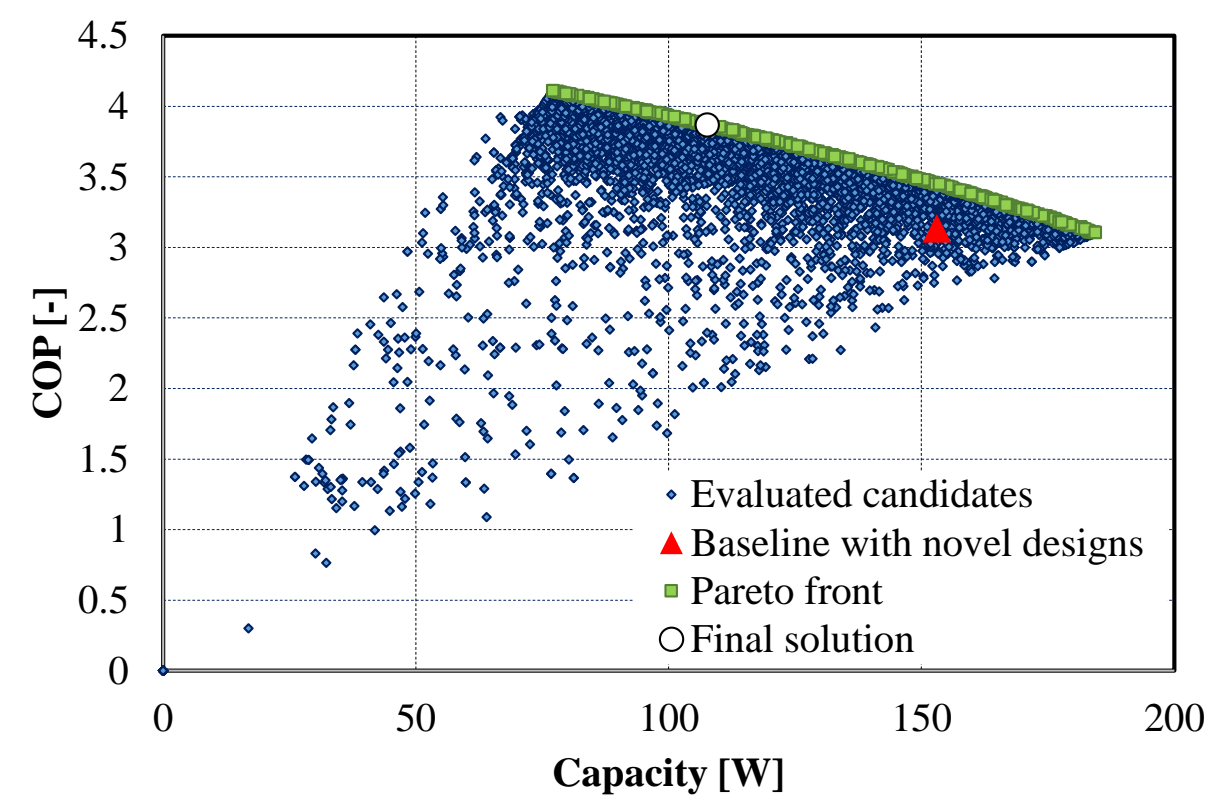

Figure 15: Multi-objective optimization results on the capacity-COP chart. 


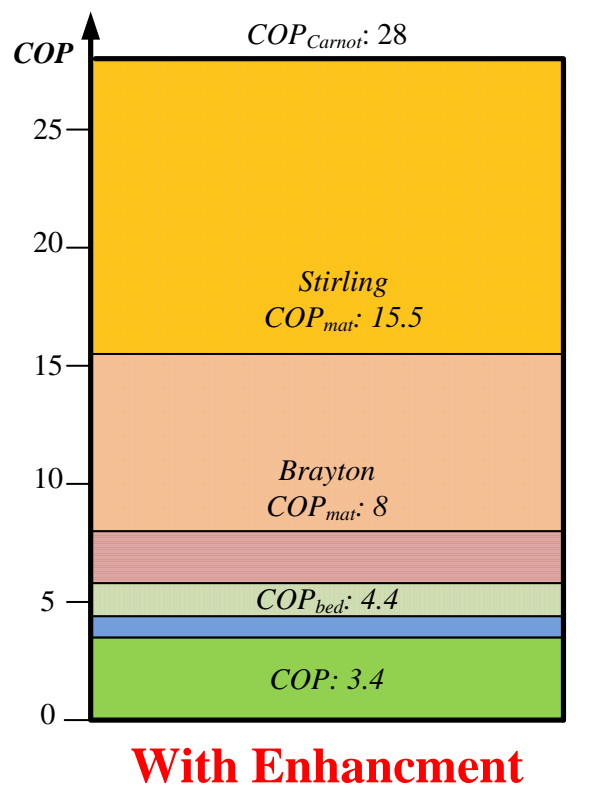

Losses contributions
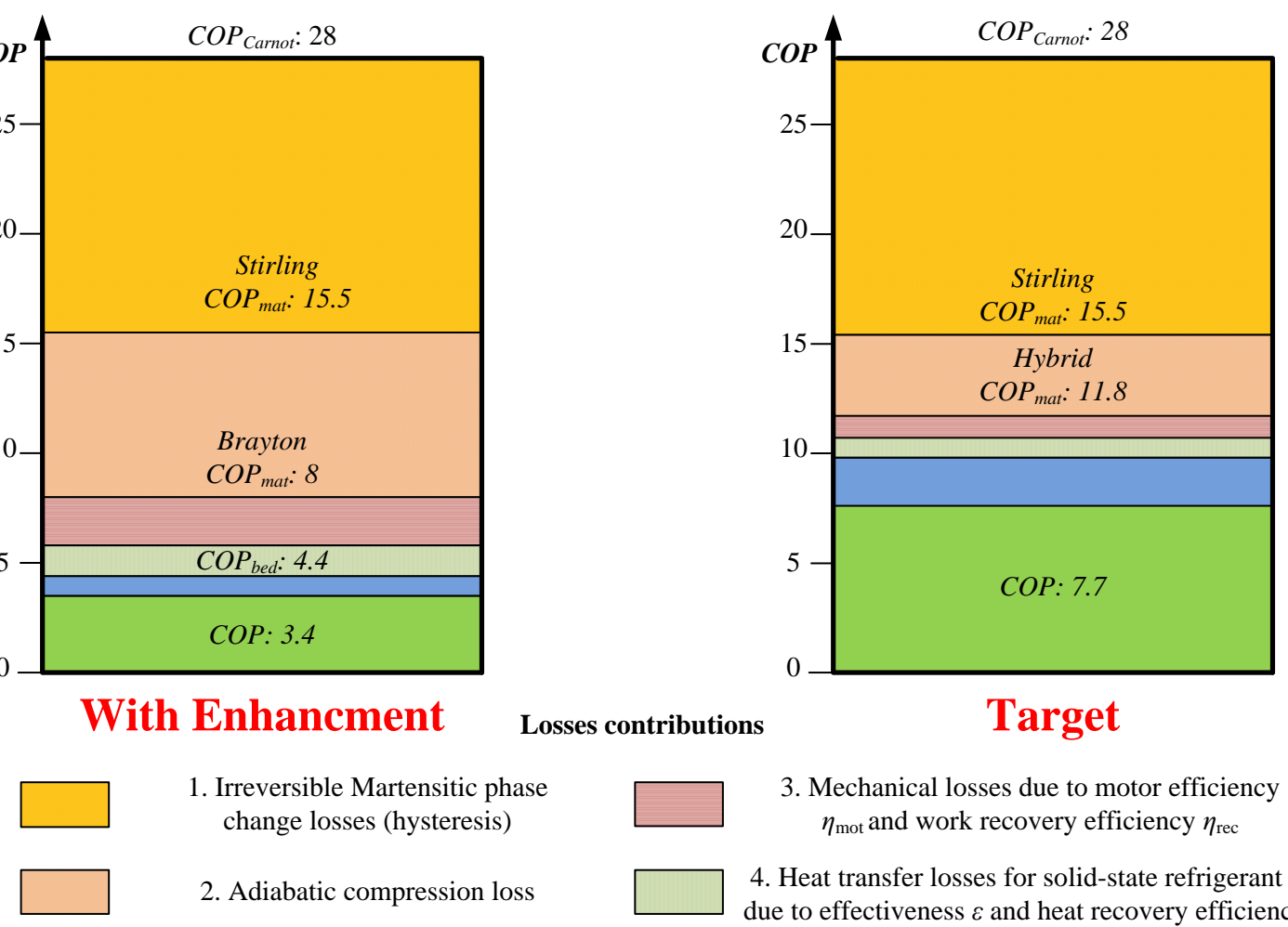

3. Mechanical losses due to motor efficiency $\eta_{\text {mot }}$ and work recovery efficiency $\eta_{\text {rec }}$

4. Heat transfer losses for solid-state refrigerant only, due to effectiveness $\varepsilon$ and heat recovery efficiency $\eta_{\mathrm{HR}}$

5. Cyclic losses and pump work

Figure 16: The updated losses analysis chart with performance enhancements as compared

to the long term target. $\left(\Delta T_{\text {lift }}=10[\mathrm{~K}]\right)$ 


\section{List of Figure Captions}

Figure 1: Thermoelastic cooling using SMA under compression mode. (Qian et al., 2015b)

Figure 2: Illustration of loss breakdown chart for a compressive thermoelastic cooling system baseline scenario operated under $10 \mathrm{~K}$ temperature lift. (Qian et al., 2015b)

Figure 3: Drawing of the baseline/original design of the SMA bed assembly using nitinol tubes under compression mode.

Figure 4: Illustration of the insulation layer design for loading head.

Figure 5: Illustration of the direct compression without loading head design.

Figure 6: Illustration of the dry loading head design.

Figure 7: Illustration of the tube-in-tube and rod-in-tube design using multiple small tubes or rods inside each regular nitinol tube.

Figure 8: Illustration of a preliminary model validation using the nitinol beds temperature measurement and comparison of the PEEK tubes implementation.

Figure 9: Flow chart of the multi-objective optimization problem solving procedure.

Figure 10: Summary of performance enhancement as results of novel designs. (all designs have the same nitinol volume and mass, $\Delta \mathrm{Tlift}=10[\mathrm{~K}], \mathrm{u}=0.8[\mathrm{~m} / \mathrm{s}], \mathrm{uHR}=0.4[\mathrm{~m} / \mathrm{s}]$, tcyc $=10$ $[\mathrm{sec}])$

Figure 11: Capacity enhancement as a result of the coating/insulation layer design. $(\Delta \mathrm{Tlift}=10$ $[\mathrm{K}], \mathrm{u}=0.8[\mathrm{~m} / \mathrm{s}], \mathrm{tcyc}=10[\mathrm{sec}])$

Figure 12: Illustration of capacity enhancement by applying plotting the exit fluid temperature of the outlet loading head using decoupling loading head design. $(\Delta \mathrm{Tlift}=5[\mathrm{~K}], \mathrm{u}=0.8[\mathrm{~m} / \mathrm{s}], \mathrm{uHR}$ $=0.4[\mathrm{~m} / \mathrm{s}]$, tcyc $=10[\mathrm{sec}])$

Figure 13: Capacity enhancement as a result of the tube-in-tube and rod-in-tube design. $(\Delta \mathrm{Tlift}=$ $10[\mathrm{~K}], \mathrm{u}=0.8[\mathrm{~m} / \mathrm{s}], \mathrm{uHR}=0.4[\mathrm{~m} / \mathrm{s}]$, tcyc $=10[\mathrm{sec}])$

Figure 14: Solutions over iterations and illustration of convergence.

Figure 15: Multi-objective optimization results on the capacity-COP chart. 
Figure 16: The updated losses analysis chart with performance enhancements as compared to the long term target. $(\Delta \mathrm{Tlift}=10[\mathrm{~K}])$ 
Table 1: Some important parameters of the baseline/original compressive thermoelastic cooling system.

\begin{tabular}{llll}
\hline & \multicolumn{3}{c}{ Geometries } \\
\hline Bed quantity [-] & 2 & Nitinol tubes per bed [-] & 19 \\
Nitinol tubes OD [m] & 0.005 & Nitinol tubes ID [m] & 0.004 \\
Nitinol tubes length [m] & 0.254 & Tubes holder diameter [m] & 0.051 \\
Loading head diameter [m] & 0.064 & Loading head depth: hexagon [m] & 0.051 \\
Loading head depth: top [m] & 0.051 & & \\
\hline & \multicolumn{2}{c}{ Properties } & 550 \\
Nitinol $\rho\left[\mathrm{kg} \cdot \mathrm{m}^{-3}\right]$ & 6,500 & Nitinol $c_{\mathrm{p}}\left[\mathrm{J} \cdot \mathrm{kg}^{-1} \cdot \mathrm{K}^{-1}\right]$ & 42 \\
Nitinol $k\left[\mathrm{~W} \cdot \mathrm{m}^{-1} \cdot \mathrm{K}^{-1}\right]$ & 18 & Nitinol entropy change $\left[\mathrm{J} \cdot \mathrm{kg}^{-1} \cdot \mathrm{K}^{-1}\right]$ & 550 \\
Stainless steel $\rho\left[\mathrm{kg} \cdot \mathrm{m}^{-3}\right]$ & 8,000 & Stainless steel $c_{\mathrm{p}}\left[\mathrm{J} \cdot \mathrm{kg}^{-1} \cdot \mathrm{K}^{-1}\right]$ & water \\
Stainless steel $k\left[\mathrm{~W} \cdot \mathrm{m}^{-1} \cdot \mathrm{K}^{-1}\right]$ & 30 & HTF & \\
\hline
\end{tabular}


Table 2: Formulation of the multi-objective optimization problem.

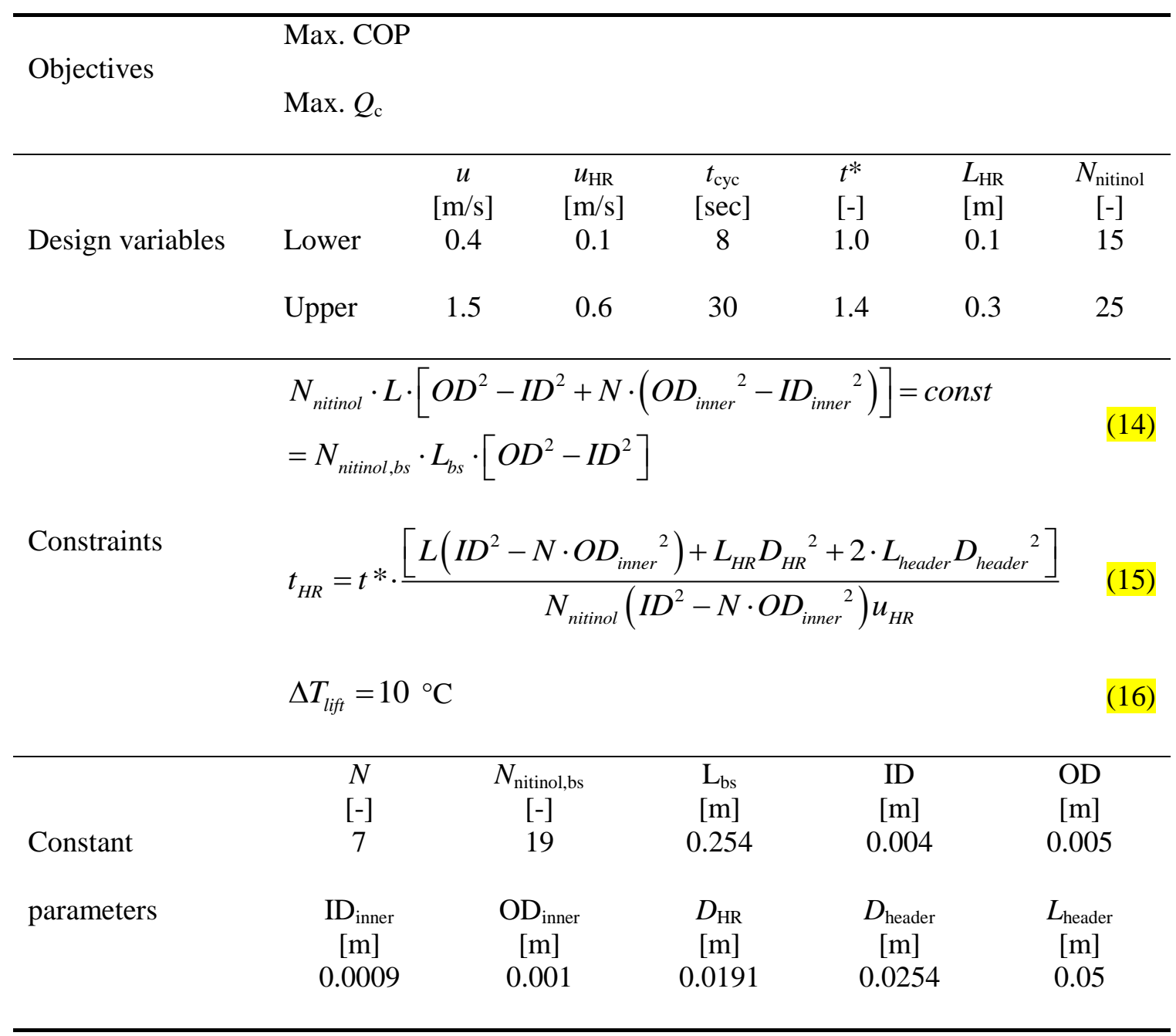


Table 3: List of four special solutions from the Pareto front as a summary of the multiobjective optimization results.

\begin{tabular}{lccccc}
\hline Baseline & Maximum COP & $\begin{array}{c}\text { Maximum } \\
\text { capacity }\end{array}$ & $\begin{array}{c}\text { Same } \\
\text { COP }\end{array}$ & $\begin{array}{c}\text { Same } \\
\text { capacity }\end{array}$ \\
\hline $\boldsymbol{Q}_{\mathbf{c}}$ & 153.1 & $77.4(-49.4 \%)$ & $\mathbf{1 8 4 . 5 ( + 2 0 . 5 \% )}$ & $\mathbf{1 8 2 . 4}(+\mathbf{+ 1 9 . 1 \% )}$ & $153.1(0 \%)$ \\
$\mathbf{C O P}$ & 3.13 & $\mathbf{4 . 1 0}(\mathbf{+ 3 0 . 8 \% )}$ & $3.10(-0.9 \%)$ & $3.13(0 \%)$ & $\mathbf{3 . 4 3}(\mathbf{+ 9 . 3 \% )}$ \\
$u$ & 0.89 & 1.04 & 1.48 & 1.47 & 1.00 \\
$\underline{u}_{\mathrm{HR}}$ & 0.40 & 0.10 & 0.36 & 0.34 & 0.23 \\
$t_{\mathrm{cyc}}$ & 10.0 & 25.2 & 8.0 & 8.2 & 10.6 \\
$t^{*}$ & 1.20 & 1.27 & 1.22 & 1.22 & 1.24 \\
$L_{\mathrm{HR}}$ & 0.25 & 0.30 & 0.30 & 0.30 & 0.30 \\
$N_{\text {nitinol }}$ & 17 & 17 & 22 & 22 & 21 \\
\hline
\end{tabular}


Table 4: Summary of the final solution on the Pareto front using the SMART decision making method.

\begin{tabular}{|c|c|c|c|c|}
\hline & $\begin{array}{c}\text { Attribute 1: } \\
\text { COP }\end{array}$ & $\begin{array}{c}\text { Attribute } 2: \\
\text { capacity }\end{array}$ & $\begin{array}{l}\text { Attribute 3: } \\
\text { frequency }\end{array}$ & $\begin{array}{l}\text { Attribute 4: } \\
\text { simplicity }\end{array}$ \\
\hline \multirow{2}{*}{ Expressions } & $\mathrm{COP}-\mathrm{COP}_{\min }$ & $Q_{\mathrm{c}}-Q_{\min }$ & $t_{\mathrm{cyc}, \max }-t_{\mathrm{cyc}}$ & $N_{\max }-N$ \\
\hline & $\mathrm{COP}_{\max }-\mathrm{COP}_{\text {min }}$ & $Q_{\mathrm{c}, \max }-Q_{\mathrm{c}, \text { min }}$ & $t_{\mathrm{cyc}, \max }-t_{\mathrm{cyc}, \min }$ & $N_{\max }-N_{\min }$ \\
\hline Weight & 0.5208 & 0.2708 & 0.1458 & 0.0625 \\
\hline \multirow{2}{*}{ Solution } & 0.759 & 0.284 & 0.476 & 0.942 \\
\hline & $\mathrm{COP}=3.87$ & $Q_{\mathrm{c}}=107.6[\mathrm{~W}]$ & $t_{\mathrm{cyc}}=17[\mathrm{sec}]$ & $N=17$ \\
\hline
\end{tabular}

